Journal of Sustainable Agricultural Sciences
http://jsas.journals.ekb.eg/

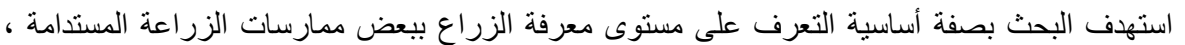

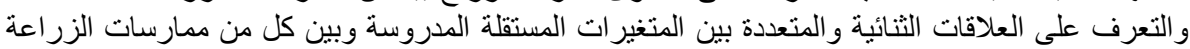

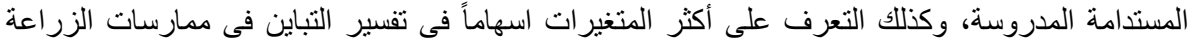

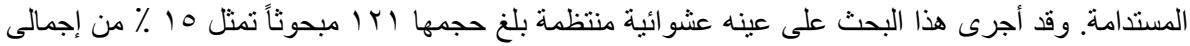

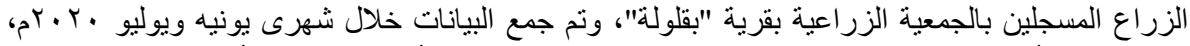

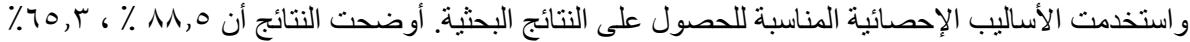

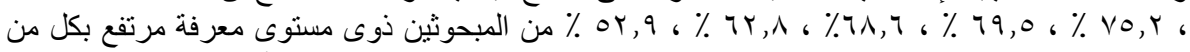

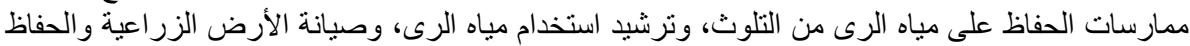

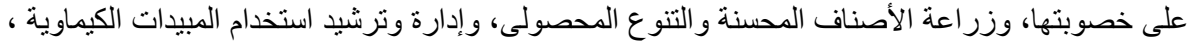

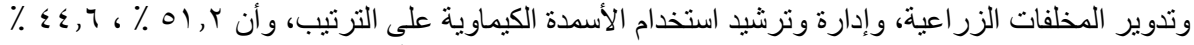

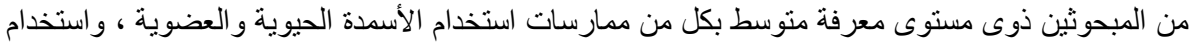

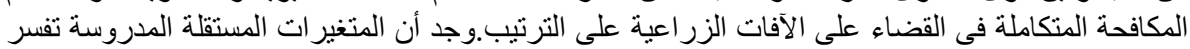

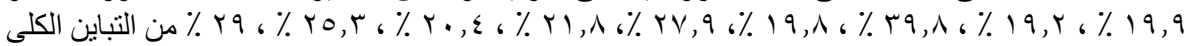

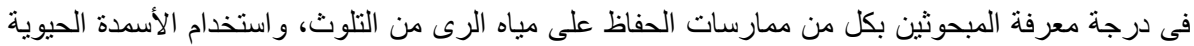

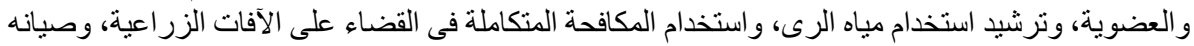

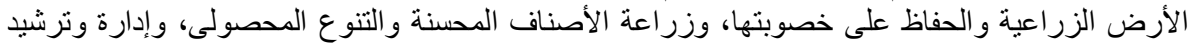

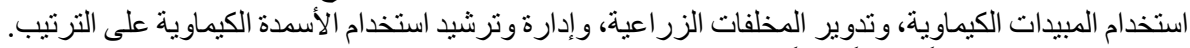

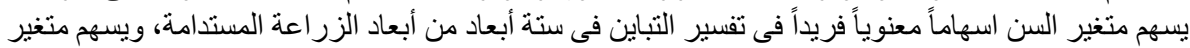

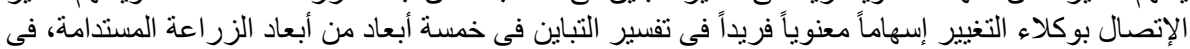

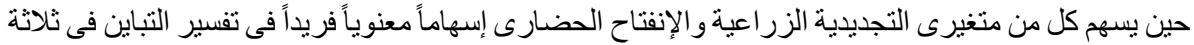
أبعاد من أبعاد الزر اعة المستدامة.
\end{abstract}

يزرع بها العالم محاصيله الغذائية يجب أن تتغير تغيراً جذرياً

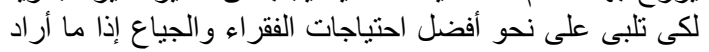

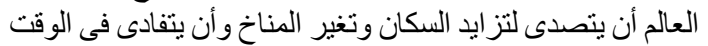

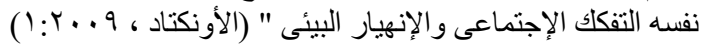
ولتحقيق ذلك كان لا بد من التخلى عن الأساليب الإنتاجية التقليدية

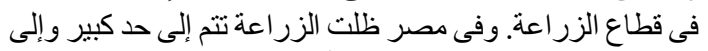

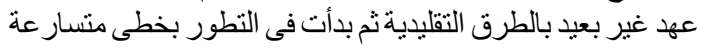

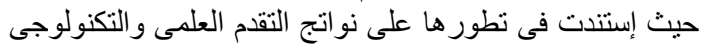

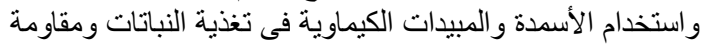

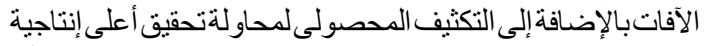

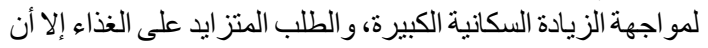

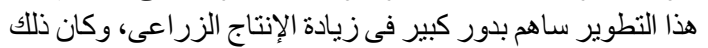

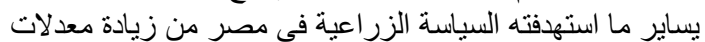

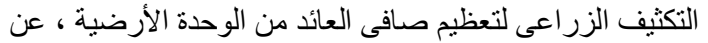

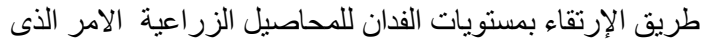

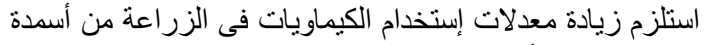

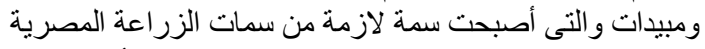

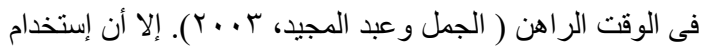

المقدمة و المشكلة البحثية

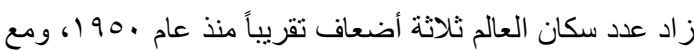

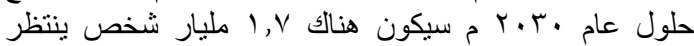

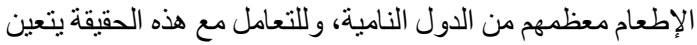

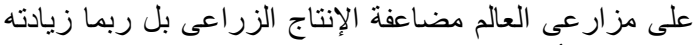

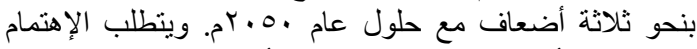

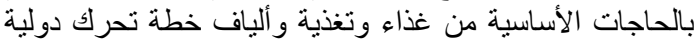

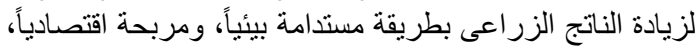

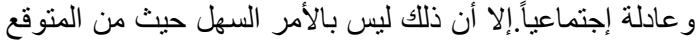

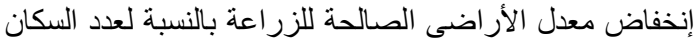

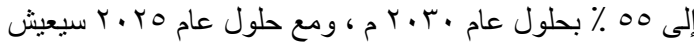

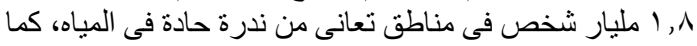

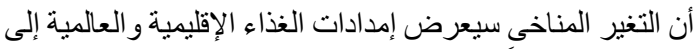

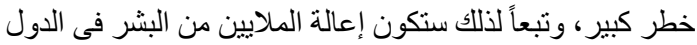
النامية محل تهديد كبير (FFO, 2011)

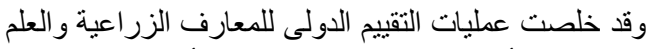
و التكنولوجيا من أجل التنمية إلى استنتاج مفاده أن " الطريقة التى للى التية 


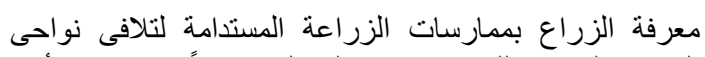

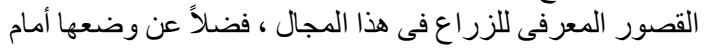

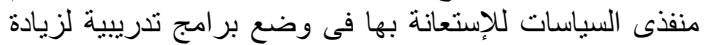

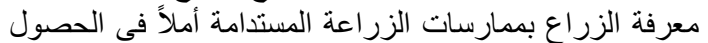
على بيئة نظيفة وغذاء آمن وصحى، والزئة والمحافظة على الموارد

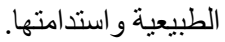

\section{الاستعر اض المرجعى والاراسات السابقة}

تعرف الإستدامةعلى أنها نموذج للتفكير حول المستقبل الذى الإنى

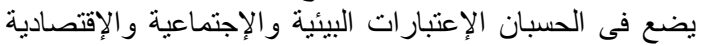

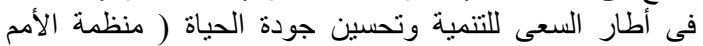

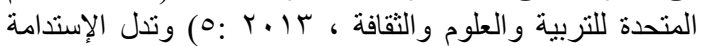

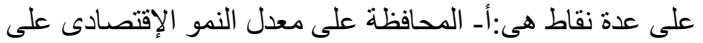

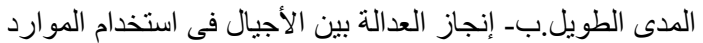

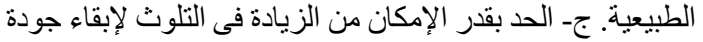

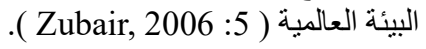

أما مفهوم الزر اعة المستدامة فقد عرفته منظمة الأغذية للأمم

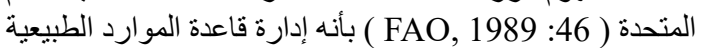

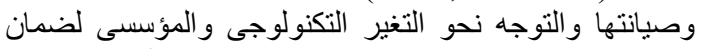
تحقيق واستمرار تلبية الإحتياجات الإنسانية للأجيال القادمة لونير

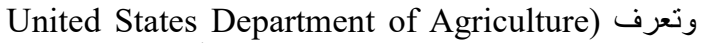

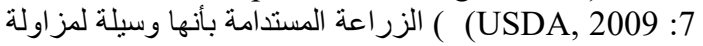

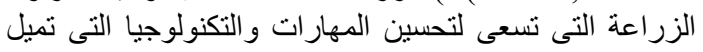

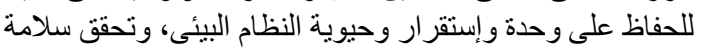

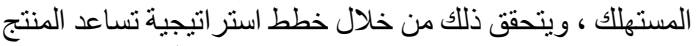

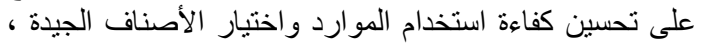

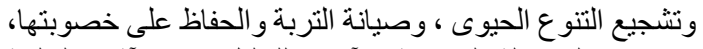

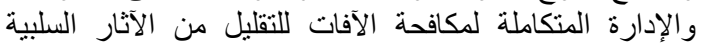

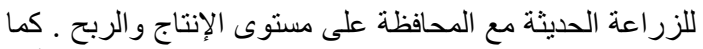

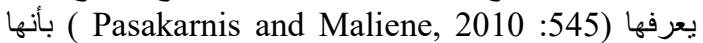
فلسفة تقوم على تحقيق الأهداف البشرية طويلة الأجل ، وهذه ) بانها

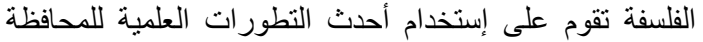

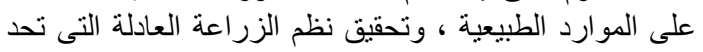

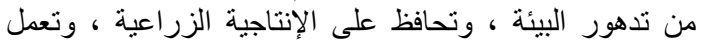

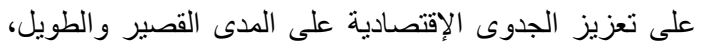

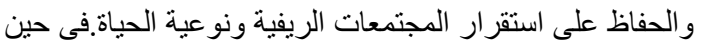

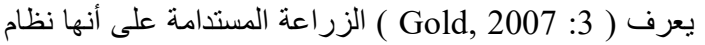

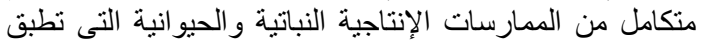

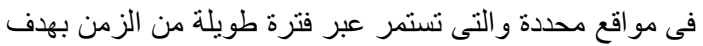

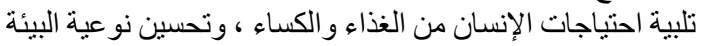

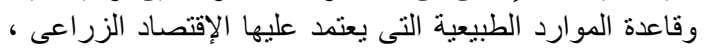

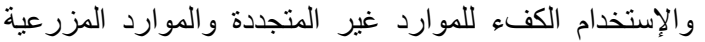

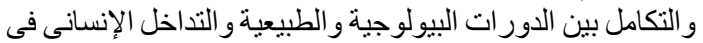

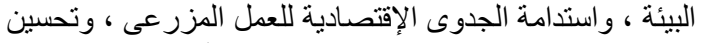
نو عية الحياة للزراع الإع والمجتمع بأسره.

وتتمثل خصائص الزر اعة المستدامة فيما يلى: الـ آمنة بئئياً:

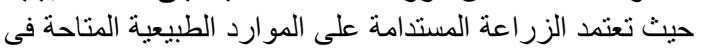

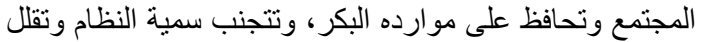

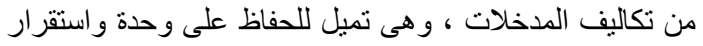

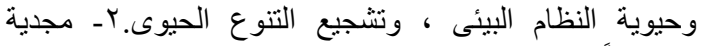

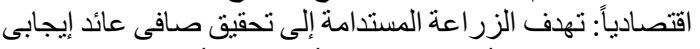

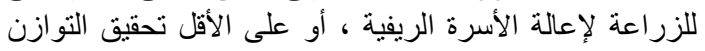

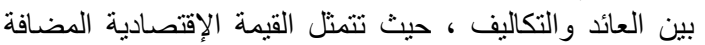

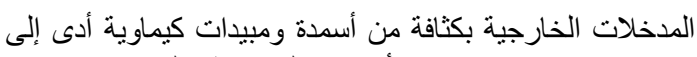

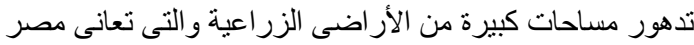

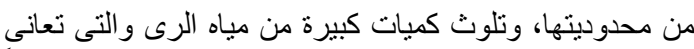

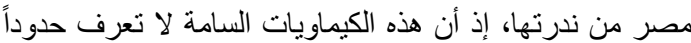

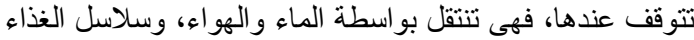

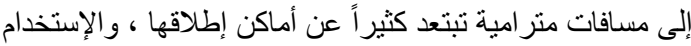

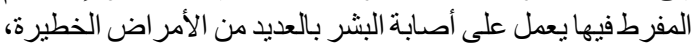

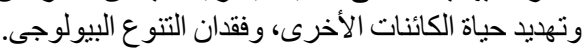

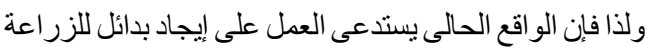

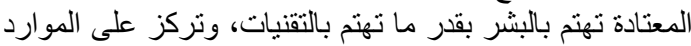

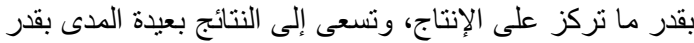

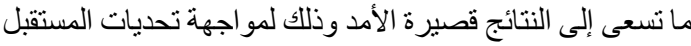

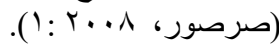

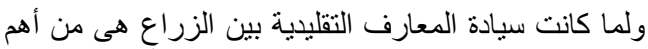

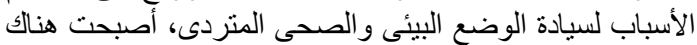

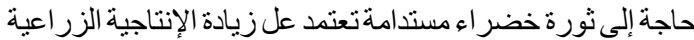

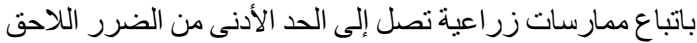

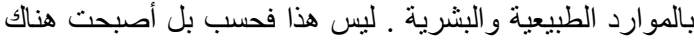

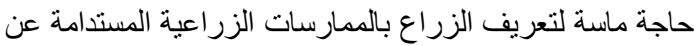

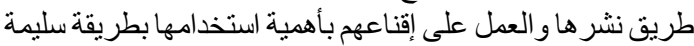
و إرشادهم إلى ذللك آخذين في الإعتبار إتجاهاتهم الثقافية والفكرية ، ومعتقداتهم الزر اعية .

أهداف البحث

النطلاقاً من العرض السابق للمشكلة البحثية يتضح أن البحث

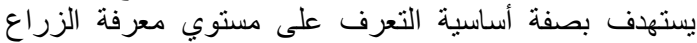
ببعض ممارسات الزر اعة المستدامة و يتحقق ذلك من خلال :

ا ـ التعرف على خصائص الزراع المبحوثين بمنطقة الدراسة.

r- التعرف على مستوى معرفة الزراع المبحوثين بممارسات

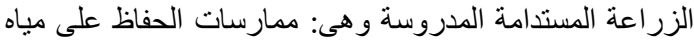

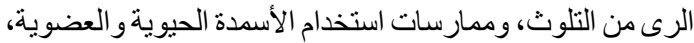

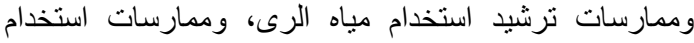

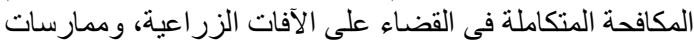

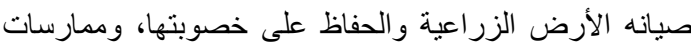

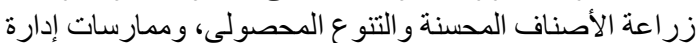

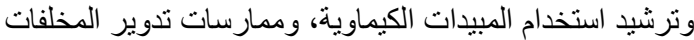
الزر اعية، وممارسات إدارة وترشيد استخدام الأسمدة الكيماوية.

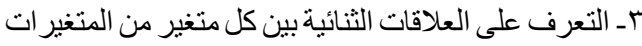

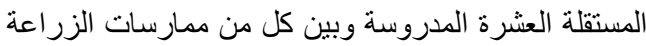
المستدامة التسعة المدروسة.

عـ التعرف على العلاقات المتعددة بين المتغيرات المستقلة

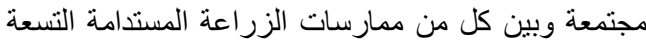
المدروسة.

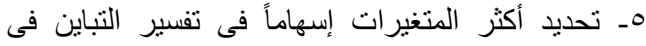
ممارسات الزر اعة المستدامة التسعة المدروسة.

أهمية البحث:

تتبع أهمية البحث فى مدى إمكانية الإستفادة من نتائج البحث

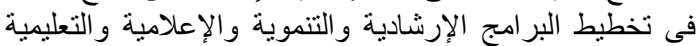

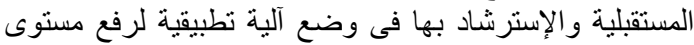

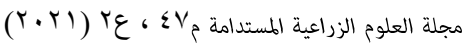


المعرفة الي ثلاثة انواع هي : معرفة الانتباه و هي معرفة الفرد

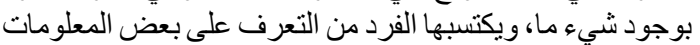

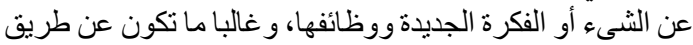

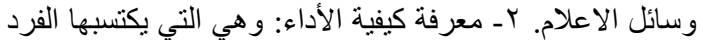

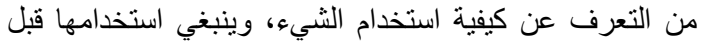

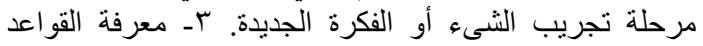

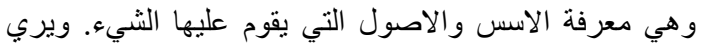

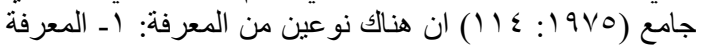

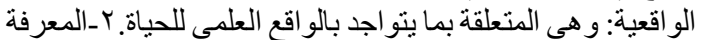

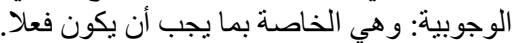

وتعتبر نظرية الفعل العقلاني من النظريات التي يمكن

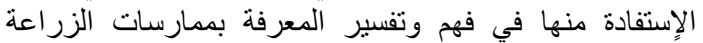

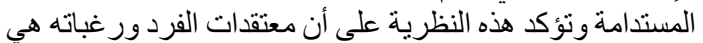

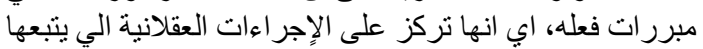

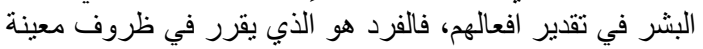

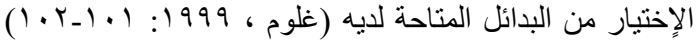

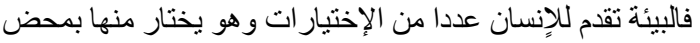

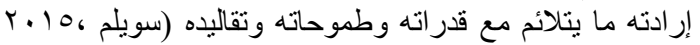
Ar:

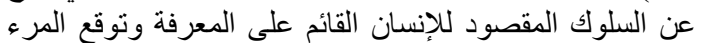

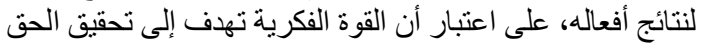

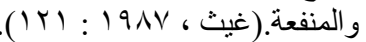

وفي ضوء ذلك يمكن القول بأن القوة الفكرية التي يمتلكها

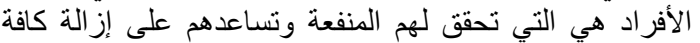

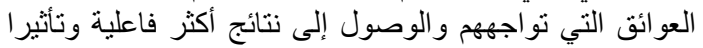

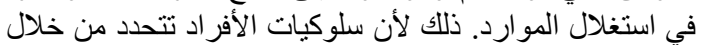

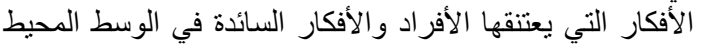

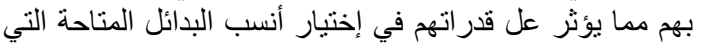

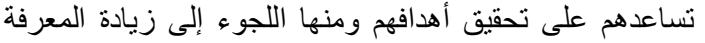

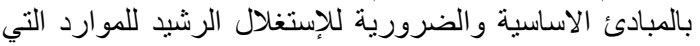

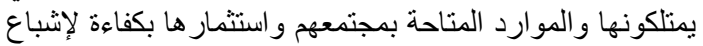

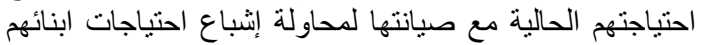

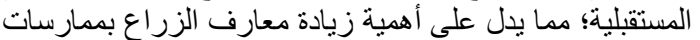

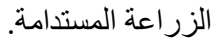

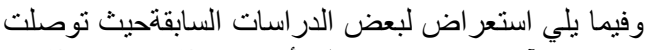

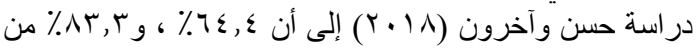

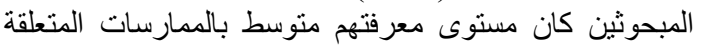

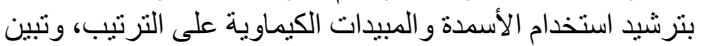

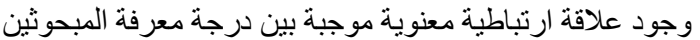

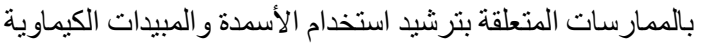

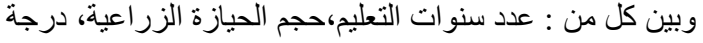

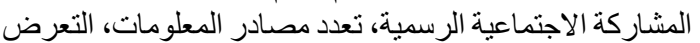
لوسائل الإعلام ، درجة الإعة الرسمية نعاركة في الأنشطة الإرشادية.

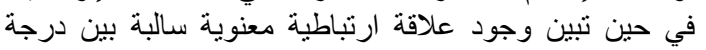
معرفة المبحوثين بالممارسات المتعلقة بترشيد استخدام الأسمدة

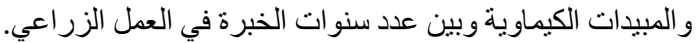

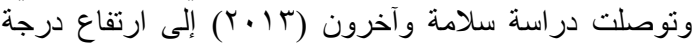

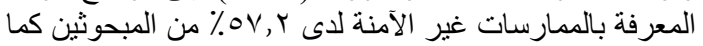

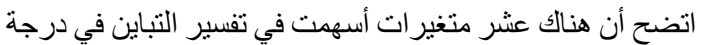

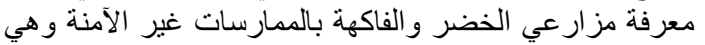

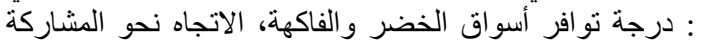

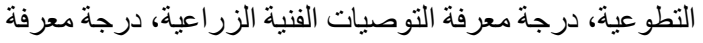
وراي المبحوث بمميزات الزرجة معرة العضويةت، معرفة التأثير

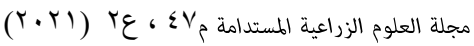

هنا فى إستغلال الموارد المتاحة ، و والحفاظ على الحياة البرية

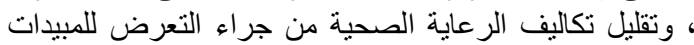

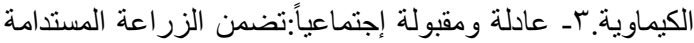

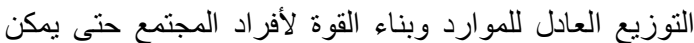

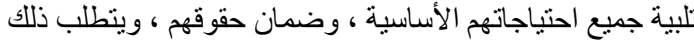

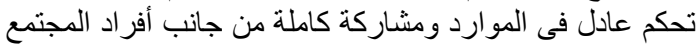

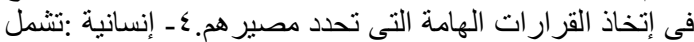

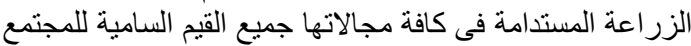

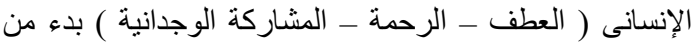

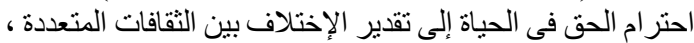

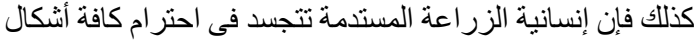

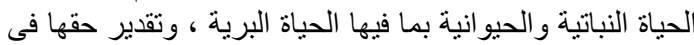

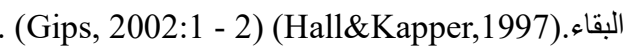

وتهدف الزر اعة المستدامة إلى: اـ تحسين الإنتاجية الراهنة

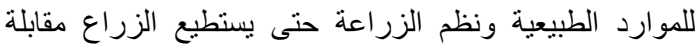

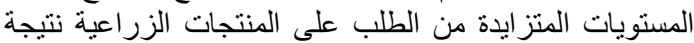

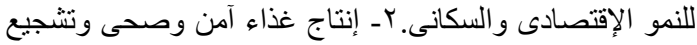

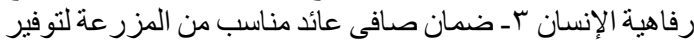

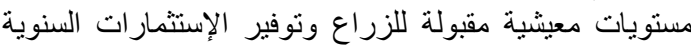

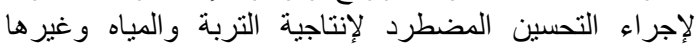
من الموارد الطبيعية. كــ الإنسجام مع معابير المجتمع ومقابلة الإنة التطلعات الإجتماعية لأفر اده. ( Corselius et al.,2001:4).

أما مجالات الزراعة المستدامة فقد عددها (Liaghoti) (et al., 2008: 228

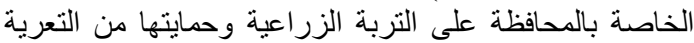

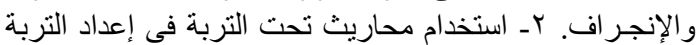

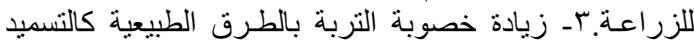

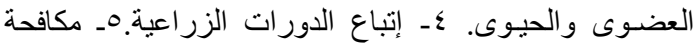

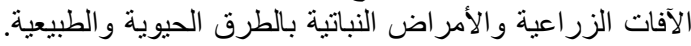

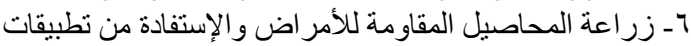

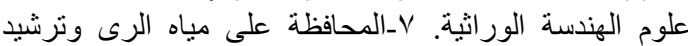

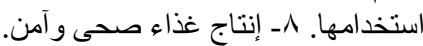

وتعرف الممارسة على أنها تكرار يؤدى لتحسن فى الأداء

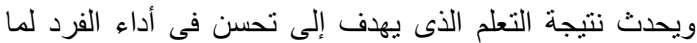

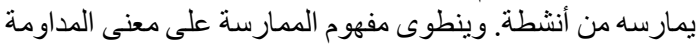

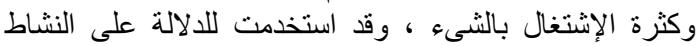

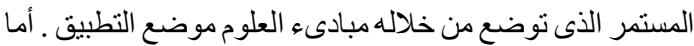

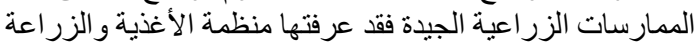

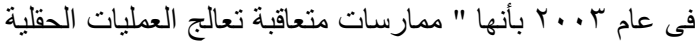

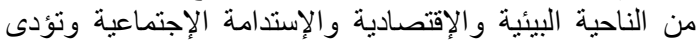

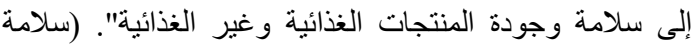

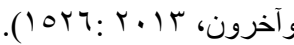

أما المعرفة فهى عبارة عن مجموعة المعانى والتصور ات ات التصان

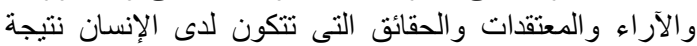

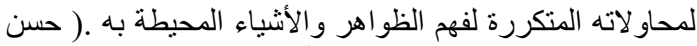

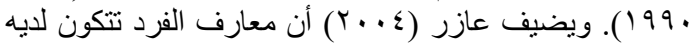

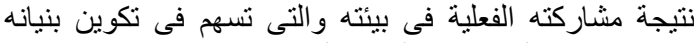

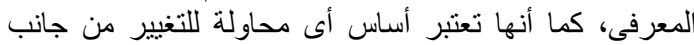

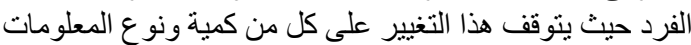

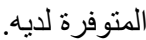

وقد قسم Rogers and Shoemaker (1971:107 أنواع 
ومعامل الإرتباط البسط ، وأسلوب الإنحدار الخطى المتعدد

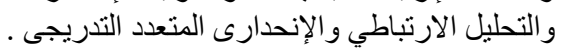

Stepwise Multiple correlation and Regression.

ثالثا : المنهج العلمى المستخدم فى البحث : استخدم المنهج الاستقرائى Inductive Approach في محاولة لتعميم النتائج

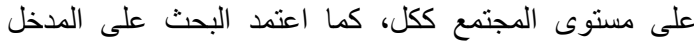
الوصفي Descriptive Method رابعاً: قياس المتغير ات البحثية: أ ـ ق قياس المتغير ات المستقلة:

1ـ ـ السن: قيس هذا المتغير بسؤال المبحوث عن سنه وقت جمع البيانات لأقرب سنة ميلادية.

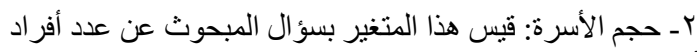

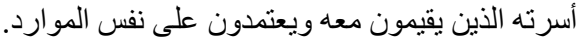

بـ عدد سنو ات الخبرة فى العمل الزر اعى: قيس هذا المتغير بقيمة

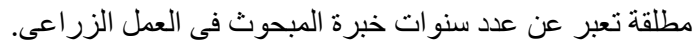

عـ حيازة الأسرة من الأرض الزر اعية: قيس هذا المتغير بسؤال

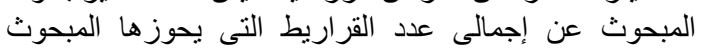
و أسرته.

0ـ حيازة الأسرة من الحيوانات المزرعية: قيس هذا المتغير

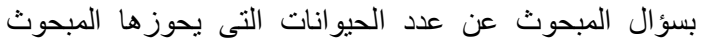

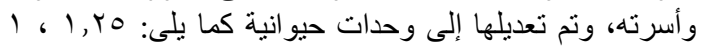

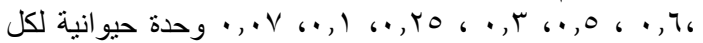

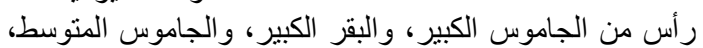

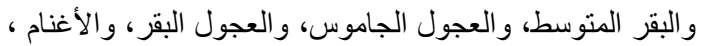

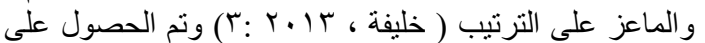

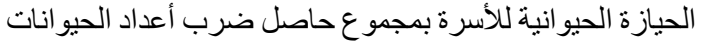
فى أوز انها المرجحة.

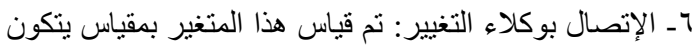

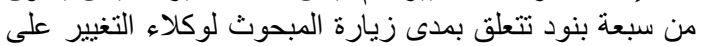

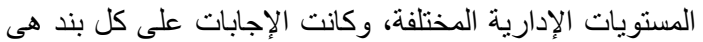

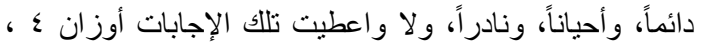

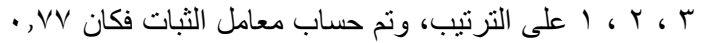

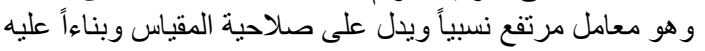
جمعت درجات البنود السبعة للحصول على على الدرجة الكلية للمتغير.

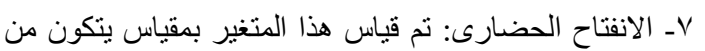

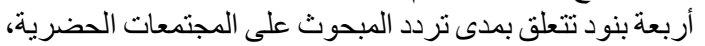

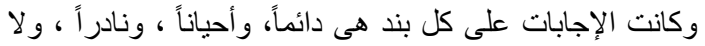

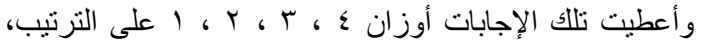

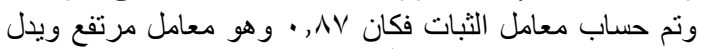

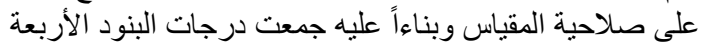
للحصول على الدرجة الكلية للمتغير.

Aـ الإتجاه نحو التخطيط للمستقبل: تم قياس هذا المتغير بمقياس

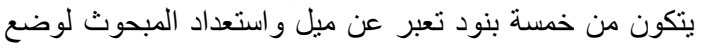

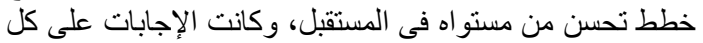

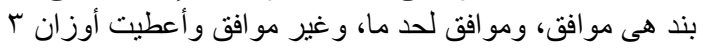

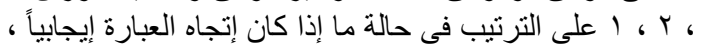

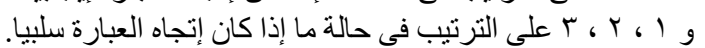

السلبي للممارسات غير الآمنة، مستوى المعيشة، الثعور بالرضا

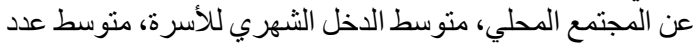

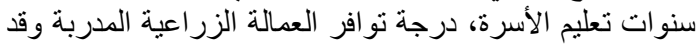

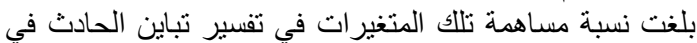

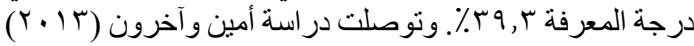

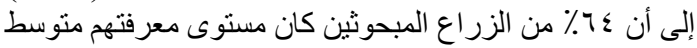

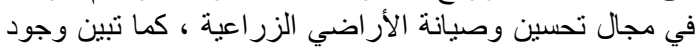

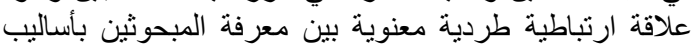

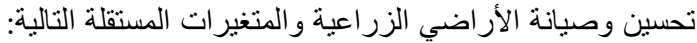

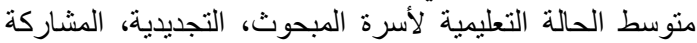

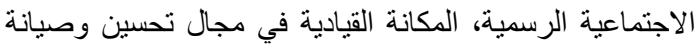

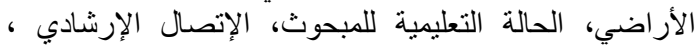

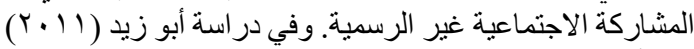

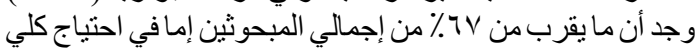

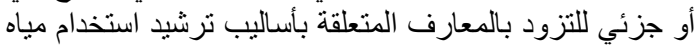

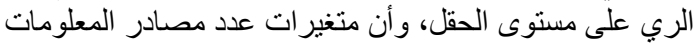

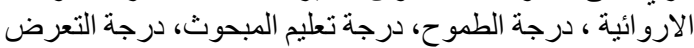

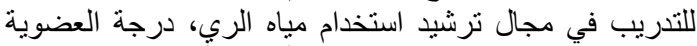

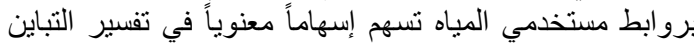

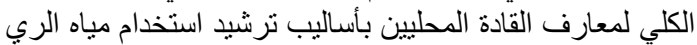

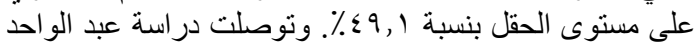

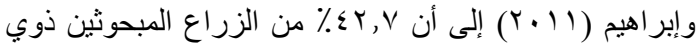

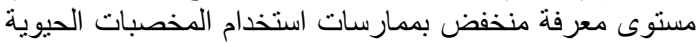

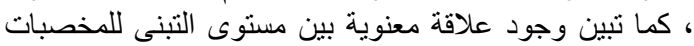

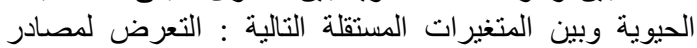

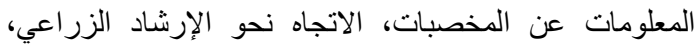

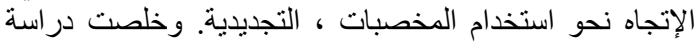

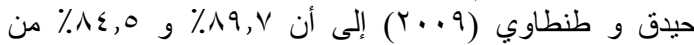

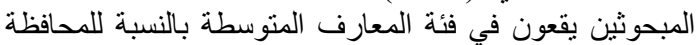

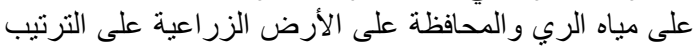

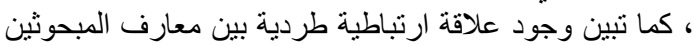

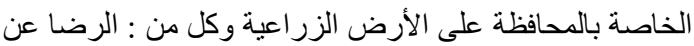

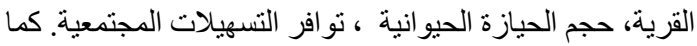

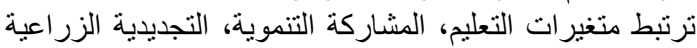

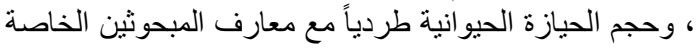
بالمحافظة على مباه الري.

الطريقة البحثبة

أو لاً: منطقة البحث و عينته: أجرى هذا البحث بمحافظة كفر الثيخ و التى تتكون من عشرة مر اكز إدارية وتم اختبار مركزاً عشو ائياً

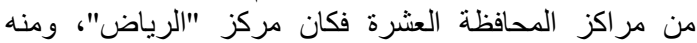

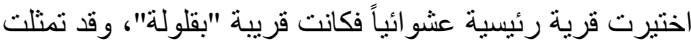

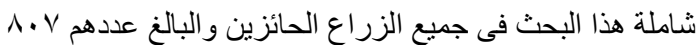

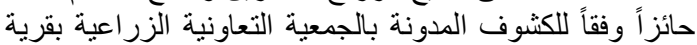

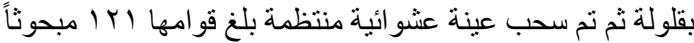
تمثل 10 \% من شاملة البحث.

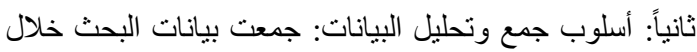

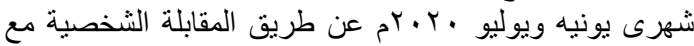

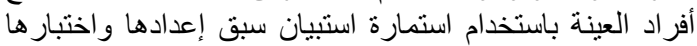

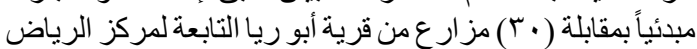

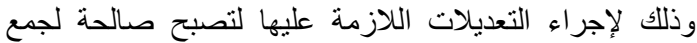

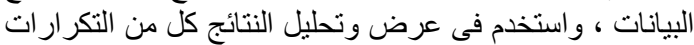

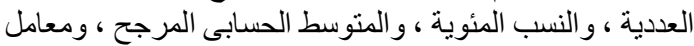

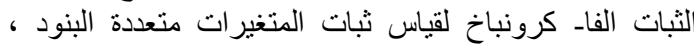

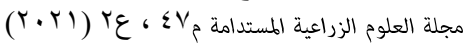


لتحقيق الاهداف الثالث و الر ابع و الخامس للار اسة تم صياغة

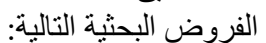
ا ـ توجد علاقة ارتباطية معنوية بين كل من المتغيرات المستقلة المدروسة وبين درجة معرفة الزراع المبحة معندة ثين الزين بممارسات الزر اعة المستدامة المدروسة.

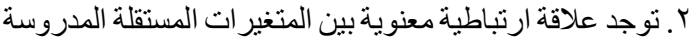

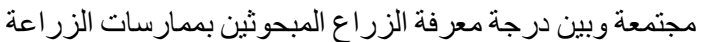

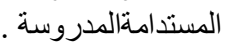
r. تسهم كل من المتغيرات المستقلة المدروسة اسهاما معنويا

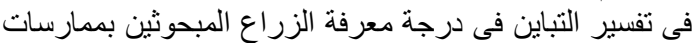

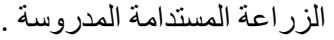

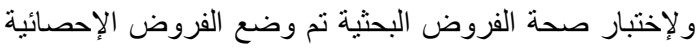
المناظرة لكل منها فى صورتها الصفرية.

النتائج ومناقشتها

او لا: خصائص الزر اع المبحوثين بمنطقة الدراسة :

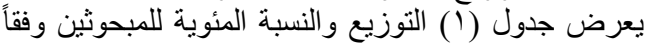

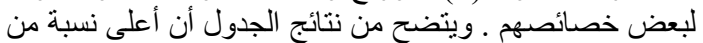

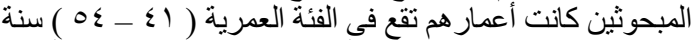

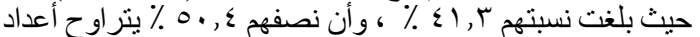

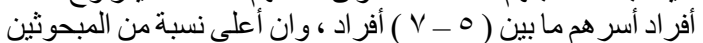

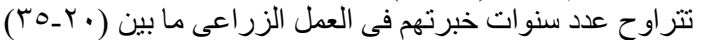

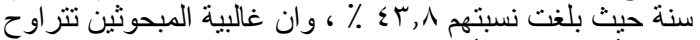

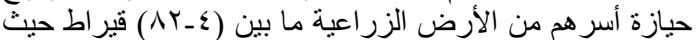

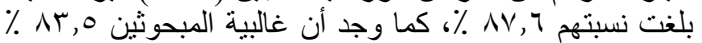

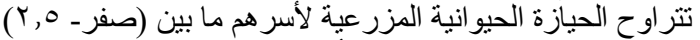

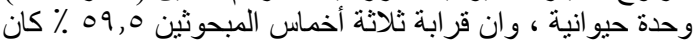

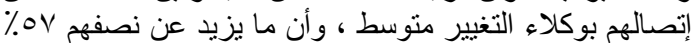

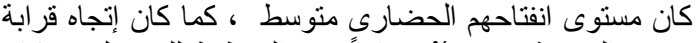

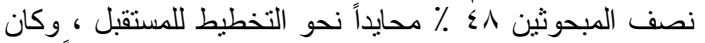

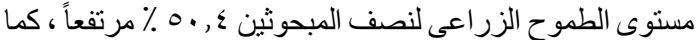

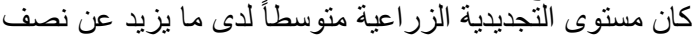

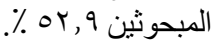

ثانيا: وصف مستويات معرفة الزراع المبحوثين بممارسات الزر اعة المستدامة وتتضمن ما يلئ:

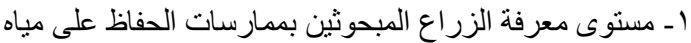

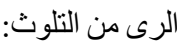

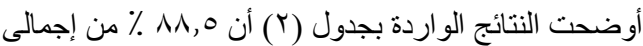

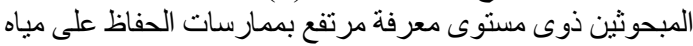

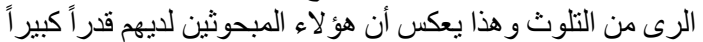

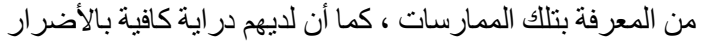

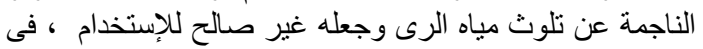

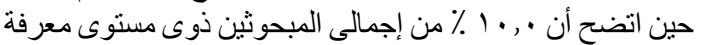

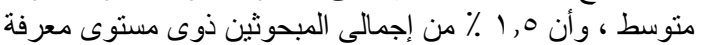

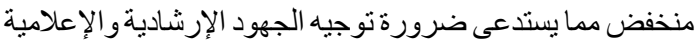

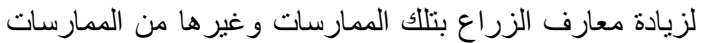

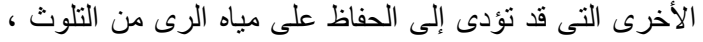

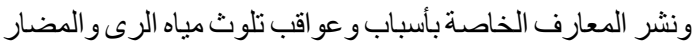

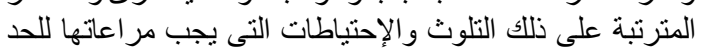

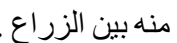

وفى محاولة للوقوف على معرفة الزراع المبحوثين بكل
وتم حساب معامل الثبات فكان • 7, · و هو معامل مقبول ويدل

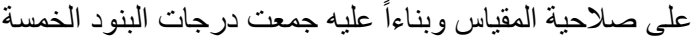
للحصول على الدرجة الكلية للمتغير.

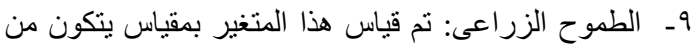

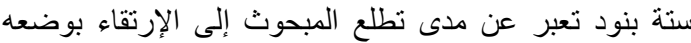

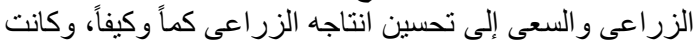

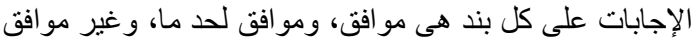

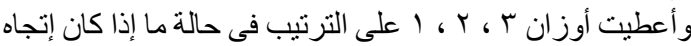

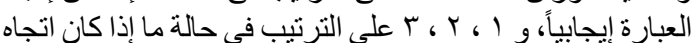

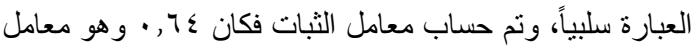
مقبول ويدل على صلاحية المقياس. وبناءً عليه جمعت درجان التهات البنود الستة للحصول على الدرجة الكلية للمتغير.

• 1ـ التجديدية الزراعية: تم قياس هذا المتغير بمقياس يتكون

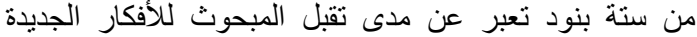

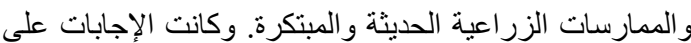

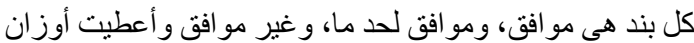

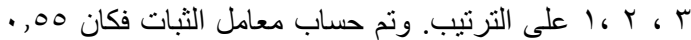

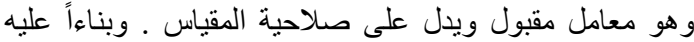
جمعت درجات البنود الستة للحصول على على الدرجة الكلية للمتغير.

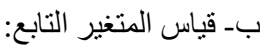

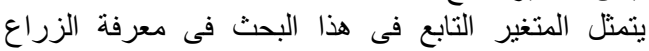

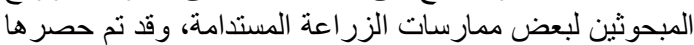

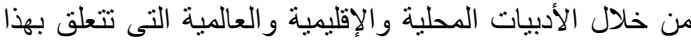

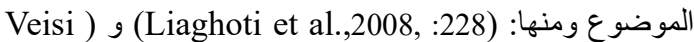

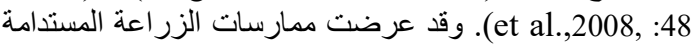

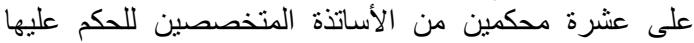

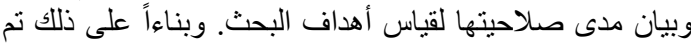

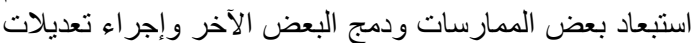

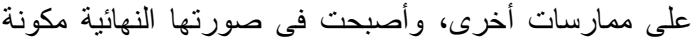

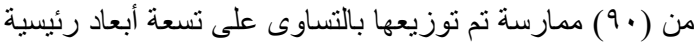

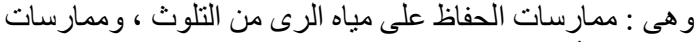

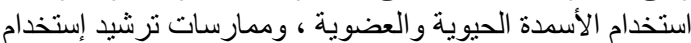

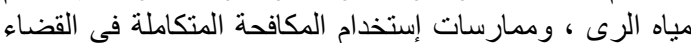
على الآفات الزراعية ، وممارسات صياتة الزيات الأرض الزية الزراعية

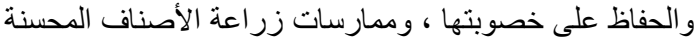
و التنوع المحصولى ، وممارسات إدارة وترشيد استخدام المبيدات

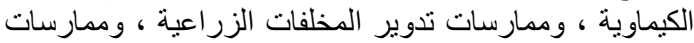

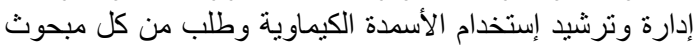

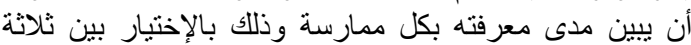

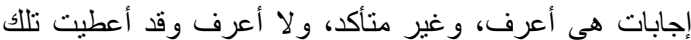

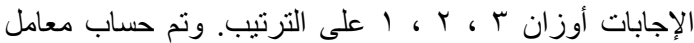

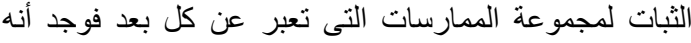

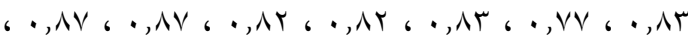

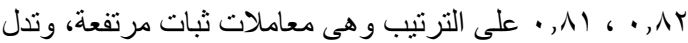

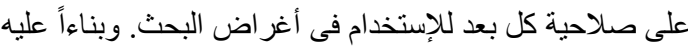
جمعت درجات كل بعد للحصول على الدرجة الكلية له. له.

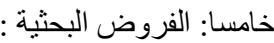


جـــــ (1 ) :التوزيع والنسبة المئوية للمبحوثين وفقاً لبعض خصائصهم

\begin{tabular}{|c|c|c|c|c|c|}
\hline$\%$ & العداد & 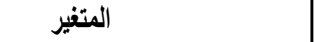 & $\%$ & 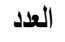 & 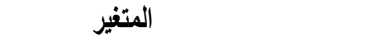 \\
\hline & & 1 - الإتصال بوكلاء التفيير: & & & 1 - السن: \\
\hline $1 \leqslant, 9$ & 11 & منخفض (V - VI ) درجة & $r q, V$ & $\leqslant \wedge$ & سنة \\
\hline 09,0 & VY & متوسط ( ؟l - Y ) درجة & $\leqslant 1, r$ & 0. & 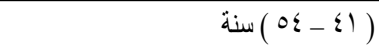 \\
\hline \multirow[t]{2}{*}{ Yo, 1} & 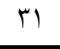 & مرتفع ( Y _ Y ) درجة & $19, \ldots$ & rr & ( \\
\hline & & | ل الإنفتاح الحضارى: & & & بَ- حجم الأسرة : \\
\hline $1 \leqslant, 9$ & 11 & منخفض ( ؛ - V) درجة & $\{0,0$ & 00 & ( فرد \\
\hline ov, & 79 & 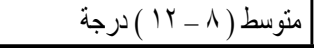 & $0 ., \varepsilon$ & 71 & فرد (V_0) \\
\hline \multirow[t]{2}{*}{$r \wedge, 1$} & $r \varepsilon$ & مرتفع (rا - 17 ) درجة & $\varepsilon, 1$ & 0 & (1 فرد \\
\hline & & 1 ــ الإتجاه نحو التخطيط للمستقبل: & & & זـ عدد سنوات الخبرة فى العطل الزراعى : \\
\hline 9, & 11 & سلبى (0 - 1 ) درجة & $\leqslant r, 1$ & 01 & ) -0 - (19 سنة \\
\hline$\{\wedge$, & 01 & محايد ( 9 - 11 ) درجة & $\varepsilon r, \Lambda$ & or & (Yo- Y. ) سنة \\
\hline \multirow[t]{2}{*}{$\leqslant \mu, \cdot$} & or & إيجابى ( I - 10 ) درجة & $1 \leqslant, 1$ & iv & 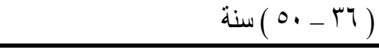 \\
\hline & & جـ الطوح الززاعى: & & & ؛ـ حيازة الأسرة من الأرض الزراعية : \\
\hline- & - & منخفض (1 - 9 ) درجة & $\Lambda V, T$ & 1.7 & صغيرة (؟ - - ص ) قبر اط \\
\hline$\leqslant 9,7$ & 7. & منوسط ( • 1 ـ ـ ) درجة & $0, \ldots$ & 7 & 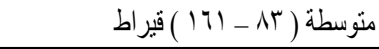 \\
\hline \multirow[t]{2}{*}{$0 ., \xi$} & 11 & مرنفع (10 _ 11 ) درجة & $\mathrm{V}, \varepsilon$ & 9 & 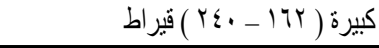 \\
\hline & & | ـ ـ التجليلية الزراعية : & & & هـ حيازة الأسرة من الحيوانات المزرعية: \\
\hline$r, r$ & $\varepsilon$ & منخفضة (1 - 9 ) درجة & $\Delta r, 0$ & 1.1 & صغيرة ( صفر - Y, ) وحدة حيو انية \\
\hline or, 9 & $7 \varepsilon$ & منوسطة ( • - ـ ـ ) درجة & $\mathbb{M}, \varepsilon$ & 10 & متوسطة ( Y, 01 - 99, ؛ ) وحدة حيو انية \\
\hline$\varepsilon r, \Lambda$ & or & | مرتفعة (10 - 11 ) درجة & $\{, 1$ & 0 & 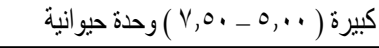 \\
\hline
\end{tabular}

جدول ץ : توزيع المبحوثين وفقاً لمستوى معرفتهم بممارسات الحفاظ على مياه الرى من التلوث

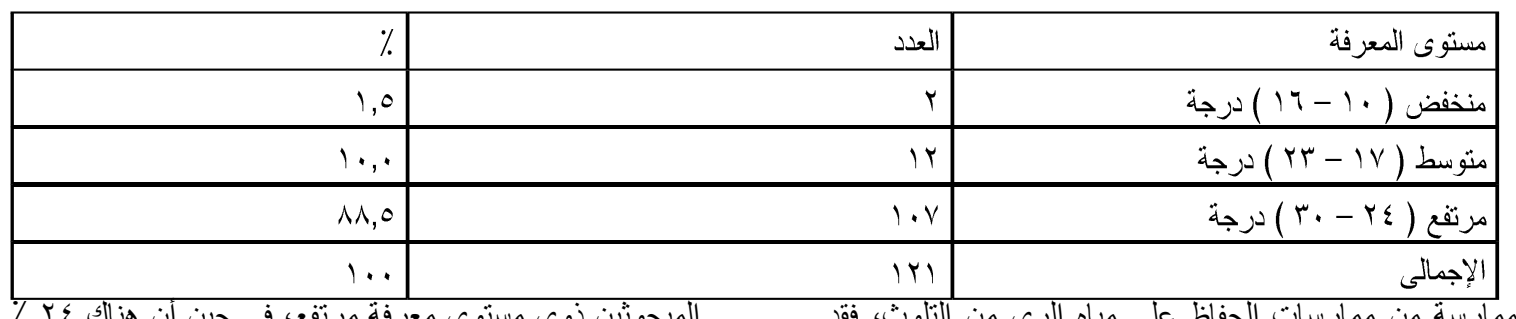

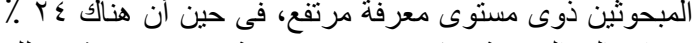

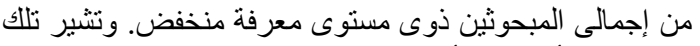

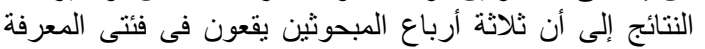

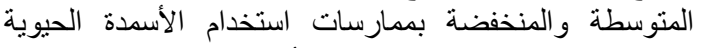

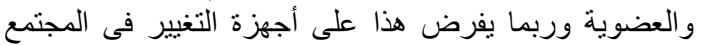

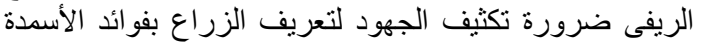

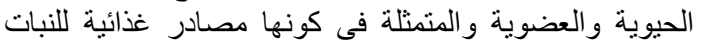

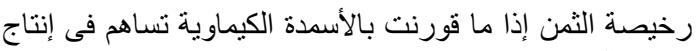

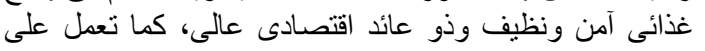

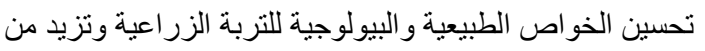

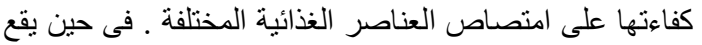

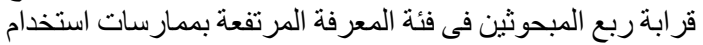

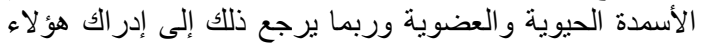

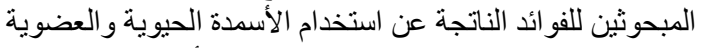

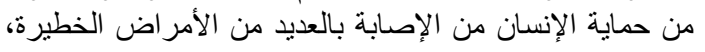

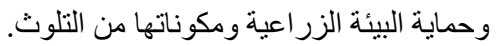
وفى محاولة للوقوف على معرفة الزراع المبنداع المبحوثين بكل

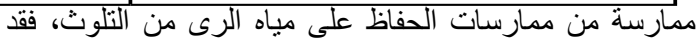

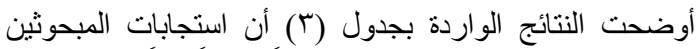

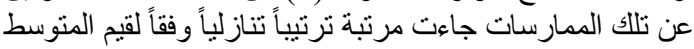

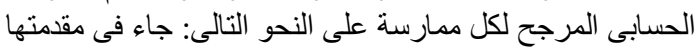

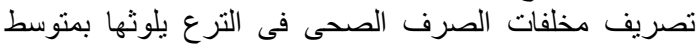

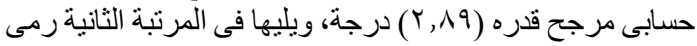

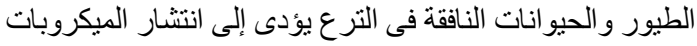

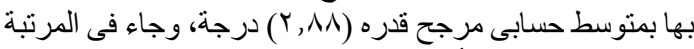

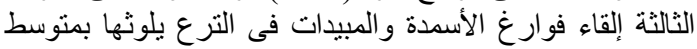

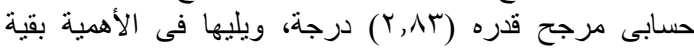

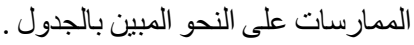

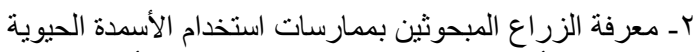

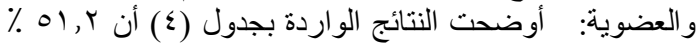

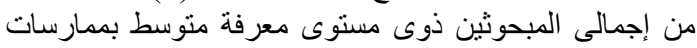

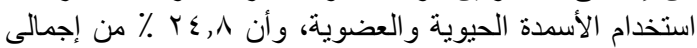


جدول (ॅ): التوزيع والنسبة المئوية للمبحوثين وفقاً لمعرفتهم بممارسات الحفاظ على مياه الرى من التلوث

\begin{tabular}{|c|c|c|c|c|c|c|c|c|}
\hline \multirow[t]{2}{*}{ الترتيب } & \multirow{2}{*}{ المنوسط الحسابى } & \multicolumn{2}{|c|}{ لا أعرف } & \multicolumn{2}{|c|}{ 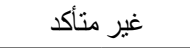 } & \multicolumn{2}{|c|}{ أعرف } & \multirow[t]{2}{*}{ ممارسات الحفاظ على مياه الرى من التلوث } \\
\hline & & $\%$ & 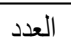 & $\%$ & 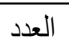 & $\%$ & 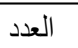 & \\
\hline 1 & $r, \wedge 9$ & $\cdot, \lambda$ & 1 & 9,1 & 11 & $9 \cdot, 1$ & 1.9 & يلوثها تصريف مخلفات الصرف الصحى فى الترع \\
\hline$r$ & $r, \Lambda \Lambda$ & $r, 0$ & $r$ & $V, \varepsilon$ & 9 & $9 \cdot, 1$ & 1.9 & 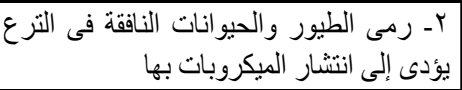 \\
\hline$r$ & $r, \Lambda r$ & $1, v$ & r & $1 \leqslant$, & IV & $\Lambda \varepsilon, \Gamma$ & 1.1 & بلون إلقاء فوارغ الأسمدة والمبيدات فى الترع \\
\hline$\varepsilon$ & $r, \wedge r$ & $r, r$ & $\varepsilon$ & 11,7 & $1 \varepsilon$ & 10,1 & 1.4 & ع ـ رمى مخلفات المحاصيل فى الترع يلوثها \\
\hline 0 & $r, \wedge$. & $0, \ldots$ & 7 & 9,9 & ir & 10,1 & 1.4 & التزـ من الضرورى عدم إلقاء القمامة المنزلية فى \\
\hline 1 & $r, Y \wedge$ & $r, 0$ & $r$ & $I V, r$ & YI & $\Lambda_{\cdot}, \mathrm{r}$ & $9 \mathrm{~V}$ & معاملة المبيدات يلوثها أو الملابس فى الترع بعد \\
\hline v & $r, Y V$ & $\varepsilon, \cdots$ & 0 & $1 \leqslant, 9$ & 11 & 11,1 & 91 & V- رمى مياه الإستعمال المنزلى فى الترع بلوثها \\
\hline$\wedge$ & $r, V 4$ & $v, \varepsilon$ & 9 & 9,1 & 11 & $\Delta r, 0$ & $1 \cdot 1$ & 1ـ غسيل و استحمام الحيو انات فى الترع يلوثها \\
\hline 9 & $r, O V$ & $\mid V, \varepsilon$ & Y) & $\Lambda, r$ & 1. & $V \varepsilon, \Gamma$ & 9. & 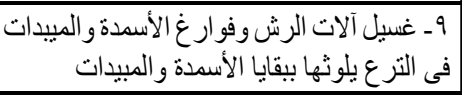 \\
\hline 1. & $r, 01$ & $M, \varepsilon$ & 10 & $r \leqslant, \ldots$ & rq & $4 \pi, T$ & VV & • 1 ـ صرف مياه الزر اعة فى الترع يضرها \\
\hline
\end{tabular}

جدول (؛ ): توزيع المبحوثين وفقاً لمستوى معرفتهم بممارسات استخدام الأسمدة الحيوية والعضوية

\begin{tabular}{|c|c|c|}
\hline$\%$ & 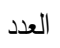 & مستوى المعرفة \\
\hline$r \varepsilon,$. & rq & منخفض (·1 - 17 ) درجة \\
\hline $01, r$ & $\pi$ & متوسط ( IV - Y ) درجة \\
\hline$r \leqslant, \Lambda$ & $r$. & 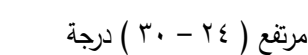 \\
\hline $1 \ldots$ & $|r|$ & ال الإجمالى \\
\hline
\end{tabular}

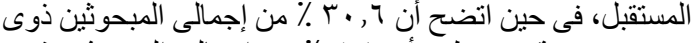

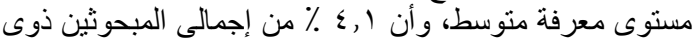

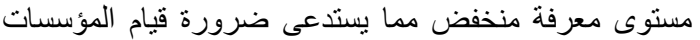

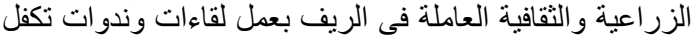

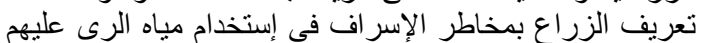

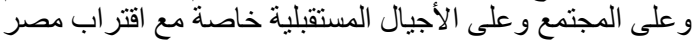
من الدخول تحت مظلة الندرة المائية.

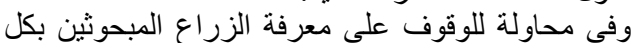

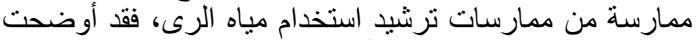

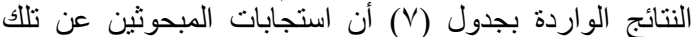

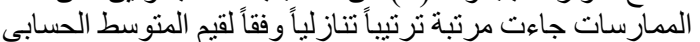

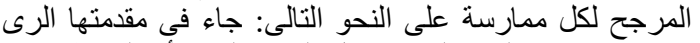

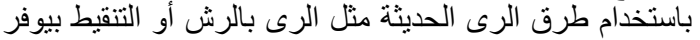

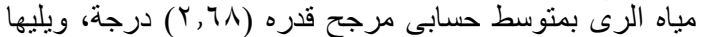

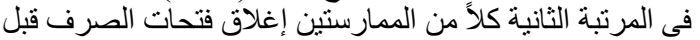

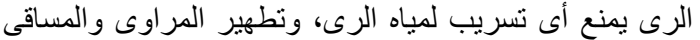

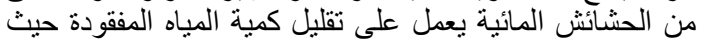

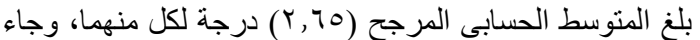

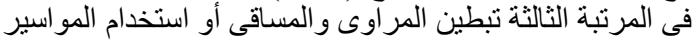

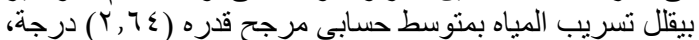

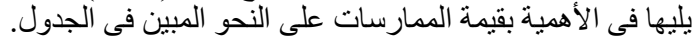

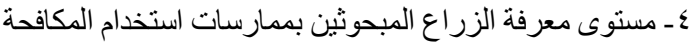
المتكاملة فى القضاء على الآفات الزر اعية:

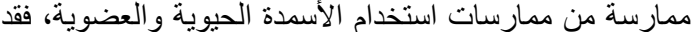

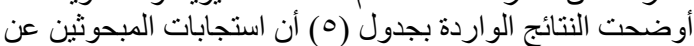

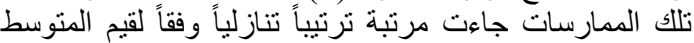

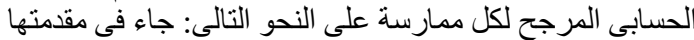

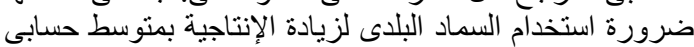

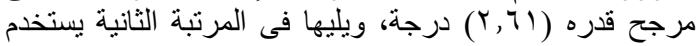

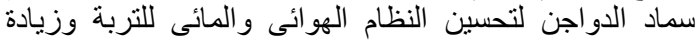

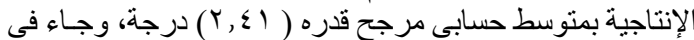

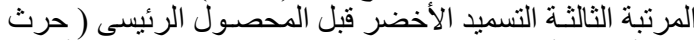

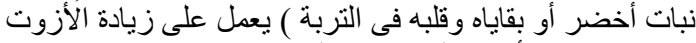

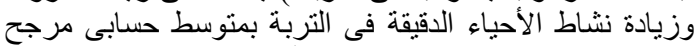

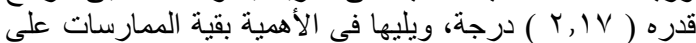

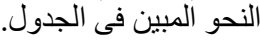

Гــ مستوى معرفة الزراع المبحوثين بممارسات ترشيد استخدام

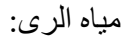

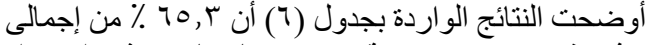
المبحوثين ذوى مستوى معرفة مرتفع بممارسات ترشيد النيد استخدام

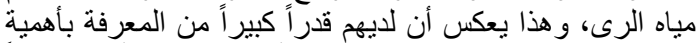

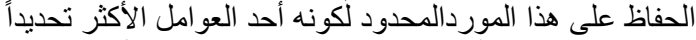

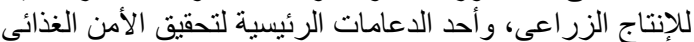

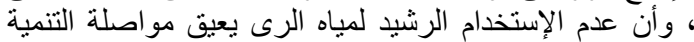
الزراعية الأفقية والرأسية، ويعرض الإنيان البلاد لأزمة مائية فى

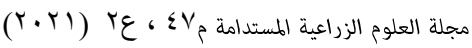


جدول (•):التوزيع والنسبة المئوية للمبحوثين وفقاً لمعرفتهم بممارسات استخدام الأسمدة الحيوية والعضوية

\begin{tabular}{|c|c|c|c|c|c|c|c|c|}
\hline \multirow{2}{*}{ الترتيب } & \multirow{2}{*}{ المتوسط الحسابى } & \multicolumn{2}{|c|}{ ل ل أعرف } & \multicolumn{2}{|c|}{ غير منتأكد } & \multicolumn{2}{|c|}{ أعرف } & \multirow[t]{2}{*}{ ممارسات استخدام الأسمدة الحيوية و العضوية } \\
\hline & & $\%$ & العدد & $\%$ & العدد & $\%$ & العدد & \\
\hline 1 & $r, T)$ & $\Lambda, r$ & 1. & $r r, r$ & rV & $79, \varepsilon$ & $\Lambda \varepsilon$ & الإنتاجية -ضرورة استخدام السماد البلدى لزيادة \\
\hline$r$ & $r, \varepsilon)$ & 19, & rr & $r \cdot, V$ & ro & $7 \cdot r$ & $V T$ & 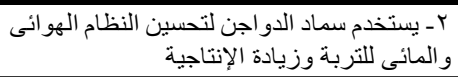 \\
\hline$r$ & $r, I V$ & $r v, r$ & Tr & $r \wedge, q$ & ro & $\varepsilon r, \Lambda$ & or & 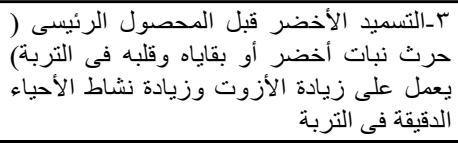 \\
\hline$\varepsilon$ & $r, 1 T$ & r , & rᄉ & $r 1,0$ & $r T$ & $\varepsilon v, 1$ & OV & العضوية بالتربة وتحسين الأسمدة الورقية ل لزيادة المادة \\
\hline 0 & $r, I r$ & $r_{0,0}$ & $\varepsilon r$ & 17,7 & $r \cdot$ & $\varepsilon v, q$ & 01 & 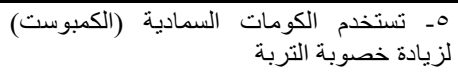 \\
\hline 7 & 1,94 & rᄉ, & $\leqslant 7$ & $r r, r$ & $r q$ & $r q, \wedge$ & דו & 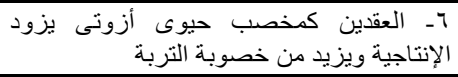 \\
\hline $\mathrm{v}$ & $1, \wedge \vee$ & $\varepsilon, 0$ & $\varepsilon 9$ & $r, r$ & $r q$ & $r V, r$ & r & 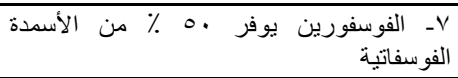 \\
\hline$\Lambda$ & $1, \wedge 1$ & $\varepsilon r, q$ & Or & Tr, & $\varepsilon$. & $r \varepsilon$, & rq & 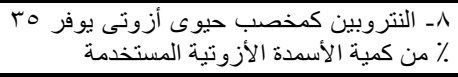 \\
\hline 9 & $1, \pi$ & $07, r$ & 71 & $r \leq, \wedge$ & $r$. & 19, & rT & 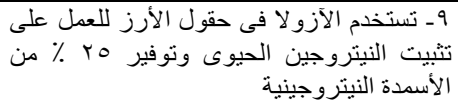 \\
\hline 1. & $1,7 r$ & $00, r$ & $7 V$ & $r v, r$ & Tr & $I V, \varepsilon$ & rI & 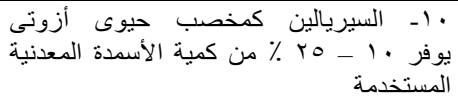 \\
\hline
\end{tabular}

جدول (†) : توزيع المبحوثين وفقاً لمستوى معرفتهم بممارسات ترشيد استخدام مياه الرى

\begin{tabular}{|c|c|c|}
\hline$\%$ & 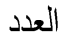 & مستوى المعرفة \\
\hline$\varepsilon, 1$ & 0 & منخفض (.1-1 1) درجة \\
\hline$r \cdot, T$ & rV & متوسط (V - Tr ) درجة \\
\hline $90, r$ & 19 & مرتقع (§ - .ب ) درجة \\
\hline
\end{tabular}

جدول (V) :التوزيع و النسبة المئوية للمبحوثين وفقاً لمعرفتهم بممارسات ترشيد استخدام مياه الرى

\begin{tabular}{|c|c|c|c|c|c|c|c|c|}
\hline \multirow[t]{2}{*}{ التزتيب } & \multirow{2}{*}{ المتوسط الحسابى } & \multicolumn{2}{|c|}{ لا أعرف } & \multicolumn{2}{|c|}{ غير متأكد } & \multicolumn{2}{|c|}{ أعرف } & \multirow[t]{2}{*}{ ممارسات ترشيد استخدام مياه الرى } \\
\hline & & $\%$ & العدد & $\%$ & العدد & $\%$ & العدد & \\
\hline 1 & $r, \uparrow \wedge$ & 7,7 & $\wedge$ & 19, & rT & $V \varepsilon, \varepsilon$ & 9. & بالرش الرى باستخيط بيوفر مياه الرى الحديثة مثل الرى \\
\hline$r$ & $r, 70$ & $\wedge, r$ & $1 \cdot$ & 19, & Tr & $V Y, V$ & $\wedge \wedge$ & تسريب لمياه الرى فتحات الصرف قبل الرى يمنع أى \\
\hline$r$ & $r, 70$ & 0,1 & $\bar{v}$ & $r \leqslant, \cdot$ & rq & $V \cdot, r$ & 10 & 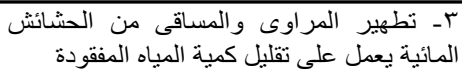 \\
\hline$r$ & $r, T \varepsilon$ & $V, \varepsilon$ & 9 & $r 1,0$ & $\overline{r T}$ & $v 1,1$ & 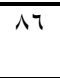 & أمو - تبير بيقل المريب المياه والمساقى أو استخدام \\
\hline$\varepsilon$ & $r, T)$ & 9,1 & 11 & $r \cdot, V$ & ro & $V \cdot, r$ & 10 & أى تـريبة للأرضاه الزر اعية أثناء الرى يتفادى \\
\hline 0 & $r, O$. & $1 \leqslant$, & iv & $r 1,0$ & $r 4$ & $T \varepsilon, 0$ & V^ & المياه تبطين الردى الأرض الزر اعية يقلل تسريب \\
\hline 7 & $r, \sum V$ & $10, \mathrm{~V}$ & 19 & $r 1,0$ & rY & $T r, \Lambda$ & $\sqrt{17}$ & كمية الرياه الليلى أو الرى فى في الصباح الباكر بيقلل \\
\hline 7 & $r, \sum V$ & $1 \leq$, & IV & $r \leqslant, \Lambda$ & $r \cdot$ & $71, Y$ & $v \varepsilon$ & المحاصيل الإلتز المختلفة بوفنات الميائية الموصى بها لرى \\
\hline $\mathrm{v}$ & $r, \varepsilon \cdot$ & $1 \wedge, Y$ & rY & $r \varepsilon, \cdot$ & rq & ov, 9 & $v \cdot$ & 9 ـ الرى على الحامى بيوفر مباه الرى \\
\hline$\wedge$ & $r, \cdot \varepsilon$ & $r \leqslant, \tau$ & $\varepsilon r$ & $r^{\prime}, \varepsilon$ & rY & $\lceil\wedge, \wedge$ & $\varepsilon V$ & • مصصول التحميل (التكثيف المحصولى) يعطى مياه \\
\hline
\end{tabular}


فضلاً عن زيادة الناتج القومى و الفردي نتيجة نجاح المكافحة وتمتع

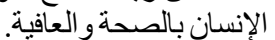

وفى محاولة للوقوف على معرفة الزراع المبحوثين بكل

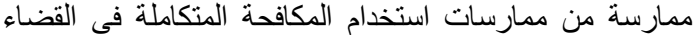

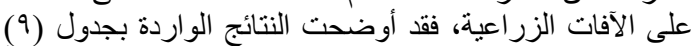

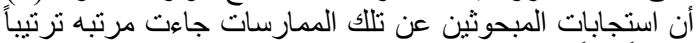

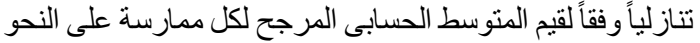

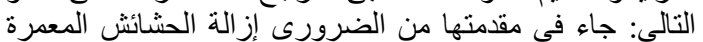

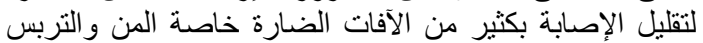

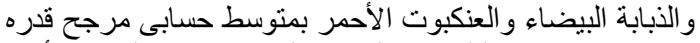

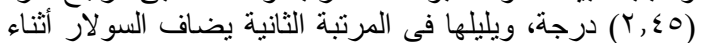

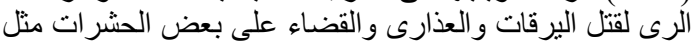

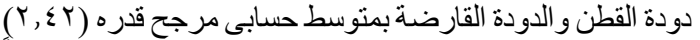

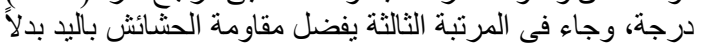

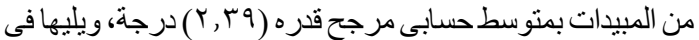
الأهمية بقية الممارسات على النحو المبين فى الجدول.

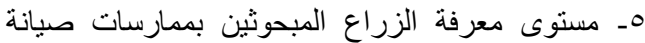

الأر اضى الزر اعية و الحفاظ على خصوبتها لئها

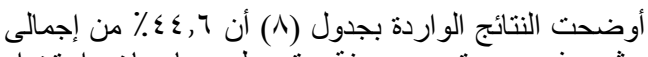

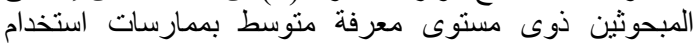

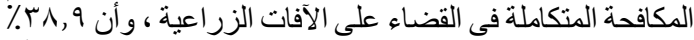

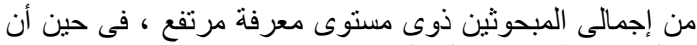

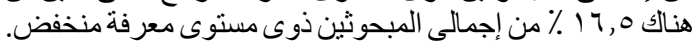

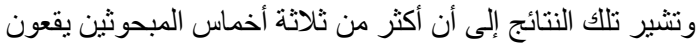

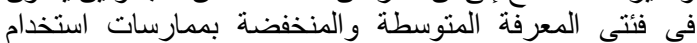

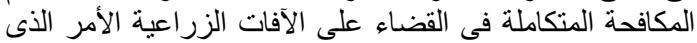

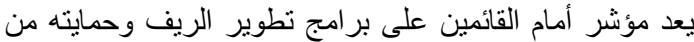

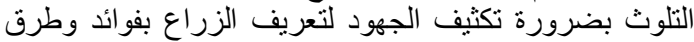

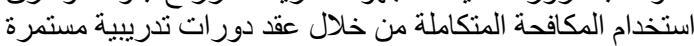

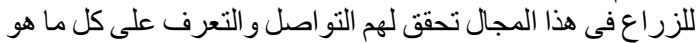

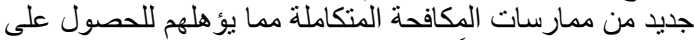

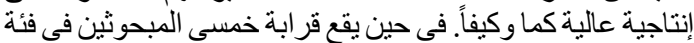

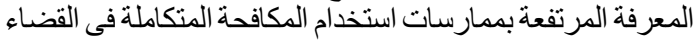
على الآفات الزر اعية وربما يرجع السبب في ذلك الك إلى الدراية الكافية

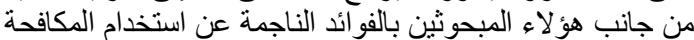

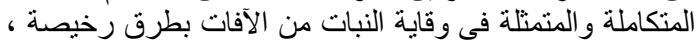

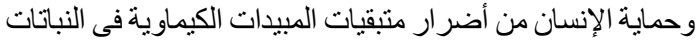
التى يتناولها ، وحماية البيئة وعناصر ها المختلفة من التلوث ،

جدول (^): توزيع المبحوثين وفقاً لمستوى معرفتهم بممارسات استخدام المكافحة المتكاملة فى القضاء على الآفات الزراعية

\begin{tabular}{|c|c|c|}
\hline$\%$ & العدد - ا & مستوى المعرفة \\
\hline 17,0 & r. & منخفض (• (1-7 1) درجة \\
\hline$\varepsilon \leqslant, 7$ & $0 \leqslant$ & منوسط (V - V T ) درجة \\
\hline$r \wedge, q$ & $\leq V$ & مرتفع (§ r - . r ) درجة \\
\hline $1 \ldots$ & $|r|$ & الإجمالى \\
\hline
\end{tabular}

جدول (9) : التوزيع والنسبة المئوية للمبحوثين وفقاً لمعرفتهم بممارسات استخدام المكافحة المتكاملة فى القضاء على الآفات الزراعية

\begin{tabular}{|c|c|c|c|c|c|c|c|c|}
\hline \multirow[t]{2}{*}{ الثرتيب } & \multirow{2}{*}{ المتوسط الحسابى } & \multicolumn{2}{|c|}{ لا أعرف } & \multicolumn{2}{|c|}{ غير متأكد } & \multicolumn{2}{|c|}{ أعرف } & \multirow{2}{*}{ القضاء على الأفات الزراعية المكافحة المتكاملة فى } \\
\hline & & $\%$ & العدد & $\%$ & العدد & $\%$ & العدد & \\
\hline 1 & $r, \leqslant 0$ & 11,7 & $1 \leq$ & $r, r, r$ & rq & $07, r$ & $\uparrow$ & 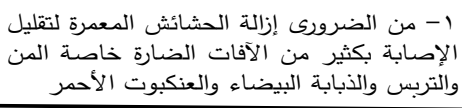 \\
\hline$r$ & $r, \varepsilon r$ & Ir, & 17 & $r_{1, \varepsilon}$ & rᄉ & $00, \varepsilon$ & TV & دوالعذارى القطن والقضودة السولار أثناء بعض الرى الحشتل اليرقات مثل \\
\hline$r$ & r, rq & $\mid v, \varepsilon$ & $r$ & $r \uparrow, \varepsilon$ & re & $07, r$ & $7 \wedge$ & المبيدات يفضل مقاومة الحشائش باليد بدلاً من \\
\hline$\varepsilon$ & $r, 19$ & $r \varepsilon, \wedge$ & $r$. & $r_{1, \varepsilon}$ & rᄉ & $\varepsilon r, \wedge$ & or & 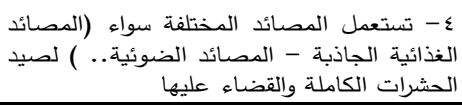 \\
\hline 0 & $r, I V$ & $r v, r$ & rT & YA,, & $r \varepsilon$ & $\varepsilon \varepsilon, 7$ & $0 \leqslant$ & هحمية يستخدم زياد الحشرات الطوائرة (العادم) كمصائد \\
\hline 7 & $r, I T$ & $r \wedge, q$ & ro & $r \wedge, q$ & ro & $\varepsilon r, r$ & 01 & 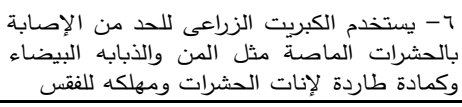 \\
\hline$v$ & $r, \cdot r$ & $r \uparrow, \varepsilon$ & $\varepsilon \varepsilon$ & $r \varepsilon_{,}$, & rq & $r q, 7$ & $\varepsilon \wedge$ & 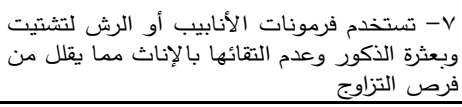 \\
\hline$\wedge$ & $r, \ldots$ & $r_{0,0}$ & $\varepsilon r$ & $r q, \cdot$ & ro & ro,o & $\varepsilon r$ & 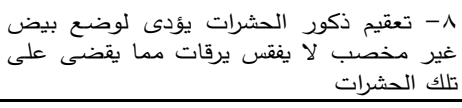 \\
\hline 9 & 1,91 & $r q, v$ & $\varepsilon \wedge$ & $r q, r$ & ru & $r \cdot, r$ & $r v$ & التغذية مما يعيق استمرار نموها لتيقيخ الحشى عليها من \\
\hline 1. & $1, \vee \wedge$ & $\varepsilon \varepsilon, 7$ & $0 \leqslant$ & rr, & $\varepsilon$. & $r, r$ & $r V$ & 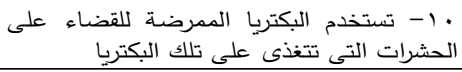 \\
\hline
\end{tabular}

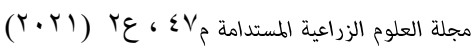


وفي محاولة للوقوف على معرفة الزراع المبحوثين بكل

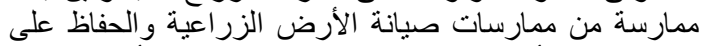

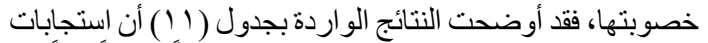

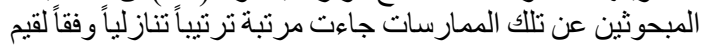

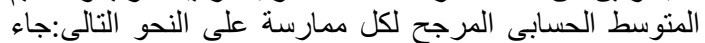
فى مقدمتها تسوية الأرض باستمر ار بشكل جيد بإنتخدام الليزر

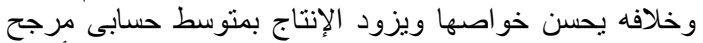

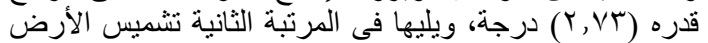

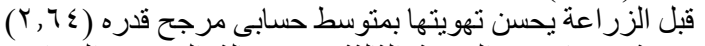

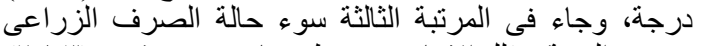

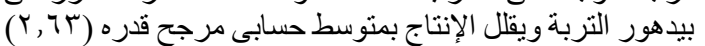

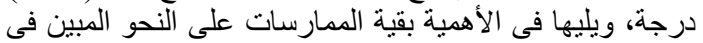

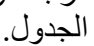
جدول ( • 1) : توزيع المبحوثين وفقاً لمستوى معرفتهم بممارسات صيانة الأرض الزراعية والحفاظ على خصوبتها

\begin{tabular}{|c|c|c|}
\hline$\%$ & 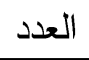 & مستوى المعرفة \\
\hline$\varepsilon, 1$ & 0 & منخفض (• (-7 1) درجة \\
\hline$r \cdot, V$ & ro & 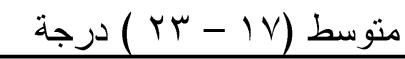 \\
\hline Vo,r & $9)$ & مرتفع (ع - - r ) درجة \\
\hline $1 \ldots$ & $|r|$ & الإجمالى \\
\hline
\end{tabular}

جدول ( 1 ) : التوزيع والنسبة المئوية للمبحوثين وفقاً لمعرفته بممارسات صيانة الأرض الزراعية والحفاظ على خصوبتها

\begin{tabular}{|c|c|c|c|c|c|c|c|c|}
\hline \multirow[t]{2}{*}{ التزتيب } & \multirow{2}{*}{ المنوسط الحسابى } & \multicolumn{2}{|c|}{ لا أعرف } & \multicolumn{2}{|c|}{ غبر متأكد } & \multicolumn{2}{|c|}{ أعرف } & \multirow{2}{*}{ خصوبتهات صيانة الأرض الزراعية والحفاظ على } \\
\hline & & $\%$ & العدد & $\%$ & العدد & $\%$ & العدد & \\
\hline 1 & $r, V r$ & 0,1 & v & $10, \mathrm{~V}$ & 19 & $\vee \wedge, 0$ & 90 & 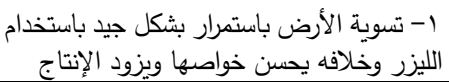 \\
\hline r & $r, 7 \varepsilon$ & $\mathrm{v}, \varepsilon$ & 9 & $r \cdot, V$ & ro & $v 1,9$ & AV & r- تثميس الأرض قبل الزراعة يحسن تهويتها \\
\hline$r$ & r & 9,9 & Kr & $\mid v, \varepsilon$ & $r$ & $V Y, Y$ & $\Lambda$ & ويقلل الإنتاج حالة الصرف الزراعى بيدهور التربة \\
\hline$\varepsilon$ & $r, T$ & $\gamma, \varepsilon$ & 9 & $r r, r$ & rA & $79, \varepsilon$ & $\wedge \varepsilon$ & 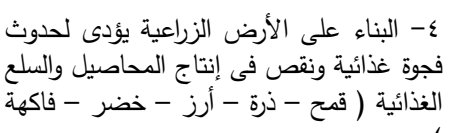 \\
\hline 。 & $r, 00$ & $1 \cdot, v$ & ir & $r \varepsilon,$. & rq & $70, r$ & vq & 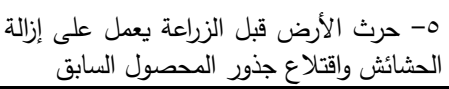 \\
\hline 1 & $r, 01$ & 9,9 & ir & $r \wedge, q$ & ro & $71, r$ & $v \varepsilon$ & 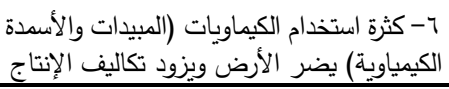 \\
\hline v & r,O. & 9,9 & Ir & $r q, \wedge$ & rq & $r, r$ & $V r$ & 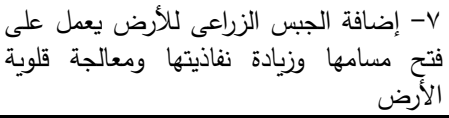 \\
\hline$\wedge$ & $r, \Sigma 9$ & $i v, \varepsilon$ & r) & 17,0 & r. & $\pi, 1$ & $\wedge$. & المنزرعبة الأرض الزراعية يقلل مساحة الأرض \\
\hline 9 & $r, \S \wedge$ & 11,7 & $1 \varepsilon$ & $r \wedge, q$ & ro & 09,0 & vi & ويضرها الأرض بمياه الصرف يقلل كفاءتها \\
\hline 1. & $r$, rq & $1 \leqslant,$. & IV & $r r, 1$ & $\varepsilon$. & or, 9 & $7 \varepsilon$ & 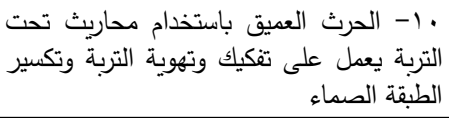 \\
\hline
\end{tabular}

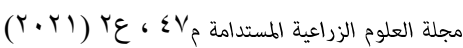

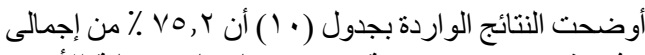

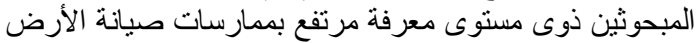

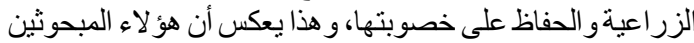

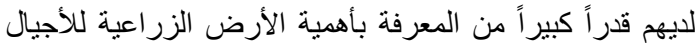

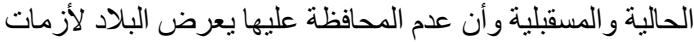

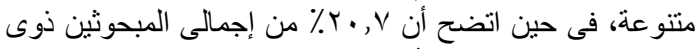

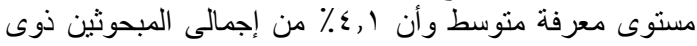

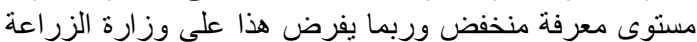

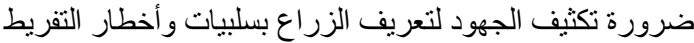

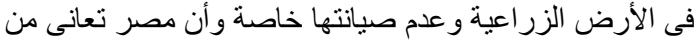
ندرة فى الأر اضى الزر الزاعية الخصبة. 
وفى محاولة لللوقوف على معرفة الزراع المبحوثين بكل

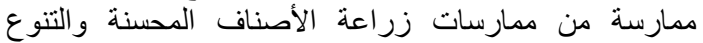

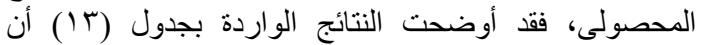

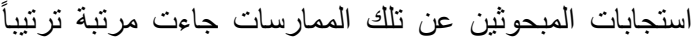

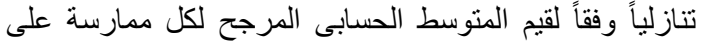

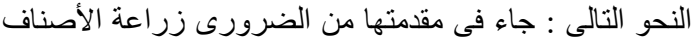

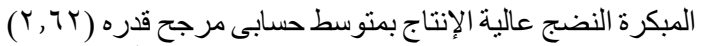

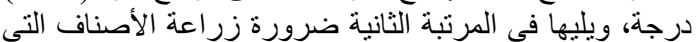

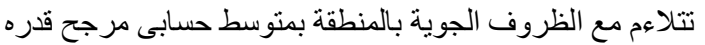

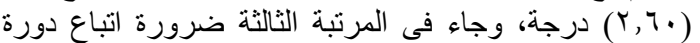

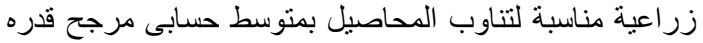

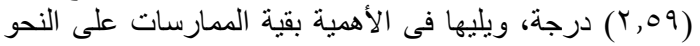

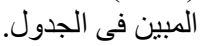

T- معرفة الزراع المبحوثين بممارسات زراعة الأصناف المحسنة والتنو ع المحصولى المئي

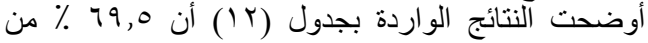

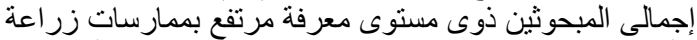

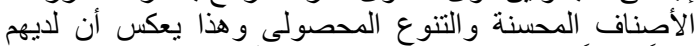

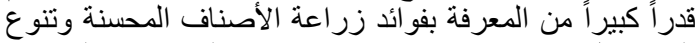

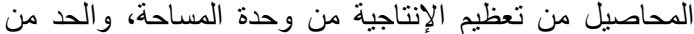

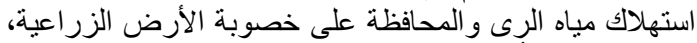

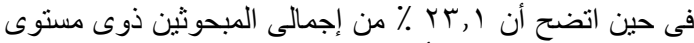

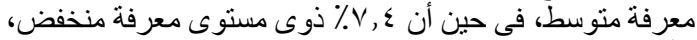

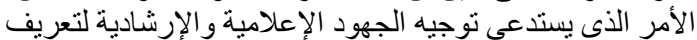

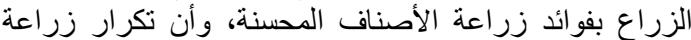

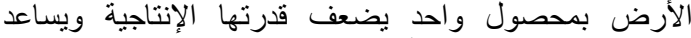

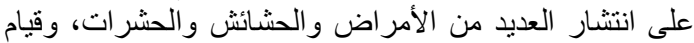
الجمعيات التعاونية الزراعية ومر اكز البحوث النقاط الزراعية بتوفير

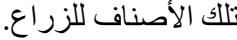

جدول (r ا ) : توزيع المبحوثين وفقاً لمستوى معرفتهم بممارسات زراعة الأصناف المحسنة والتتوع المحصولى

\begin{tabular}{|c|c|c|}
\hline$\%$ & العدد ال العد & مستوى المعرفة \\
\hline$V, \varepsilon$ & 9 & منخفض (•(1-7 () درجة \\
\hline rr, & r^ & 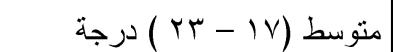 \\
\hline 79,0 & $\Lambda \varepsilon$ & مرتفع (乏乏 - بr ) درجة \\
\hline $1 \ldots$ & $|r|$ & الإجمالى الى \\
\hline
\end{tabular}

جدول (r ا ) : التوزيع والنسبة المئوية للمبحوثين وفقاً لمعرفتهم بممارسات زراعة الأصناف المحنة والتنوع المحصولى

\begin{tabular}{|c|c|c|c|c|c|c|c|c|}
\hline \multirow[t]{2}{*}{ الترتيب } & \multirow{2}{*}{ المتوسط الحسابى } & \multicolumn{2}{|c|}{ لا أعرف } & \multicolumn{2}{|c|}{ غير متأكد } & \multicolumn{2}{|c|}{ أعرف } & \multirow{2}{*}{ المحصولى زراعة الأصناف المحسنة والتتوع } \\
\hline & & $\%$ & العدد & $\%$ & العدد & $\%$ & العدد & \\
\hline 1 & $r, \pi r$ & $1 \cdot, v$ & ir & 17,0 & $r$. & $V Y, A$ & $\wedge \wedge$ & النضج عن الضرورى زلإنتاج زاعة الأصناف المبكرة \\
\hline r & r, . . & $1 \cdot, v$ & ir & $19,$. & r & $v \cdot, r$ & 10 & الظروف الجوية بالمنطقة الأصناف التى تتلاءم مع \\
\hline$r$ & $r, 09$ & $M, r$ & 17 & $1 \leqslant, 9$ & 11 & $v 1,9$ & $\lambda V$ & المحاصيل ضرورة اتباع دورة زراعية مناسبة لتناوب \\
\hline$\varepsilon$ & $r, 00$ & $10, \mathrm{~V}$ & 19 & Ir, & 17 & $v 1,1$ & $\wedge 4$ & عليها ويزود الإنتاج الماف المائمة لنوع التربة يحافظ \\
\hline 。 & r,or & $1 \leqslant$, & iv & 19,9 & $r \leq$ & 77,1 & $\wedge$. & المحسنة يزود الأصناجية ذات الصفات الوراثية \\
\hline 。 & r,or & $M, r$ & 17 & $r, 0$ & $r t$ & $70, r$ & vq & موثوقة استخدام التقاوى المنتقاه ومن مصادر \\
\hline 7 & $r, 01$ & $1 \leqslant, 9$ & 11 & $19,$. & $r$ & $7 \pi, 1$ & $\wedge$. & انتشارها زراعة الأصناف المقاومة للآفات يحد من \\
\hline v & $r, \leqslant \wedge$ & 11,7 & $1 \varepsilon$ & $r \wedge, q$ & ro & 09,0 & VY & 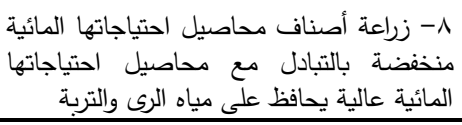 \\
\hline$\wedge$ & $r, r \varepsilon$ & 17,0 & $r$. & Ir, & $\varepsilon$. & $0 ., \varepsilon$ & $\pi$ & 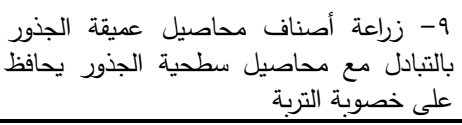 \\
\hline 9 & $r, r \varepsilon$ & $r \varepsilon, \wedge$ & $r$. & $r \hookrightarrow, \varepsilon$ & rr & $\varepsilon \wedge, \wedge$ & 09 & 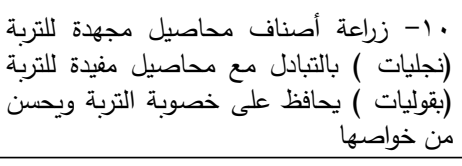 \\
\hline
\end{tabular}

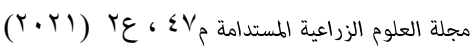


وفى محاولة للوقوف على معرفة الزراع المبحوثين بكل

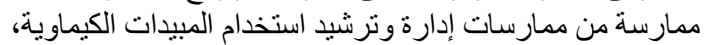

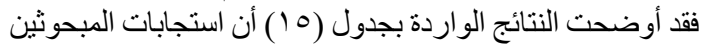

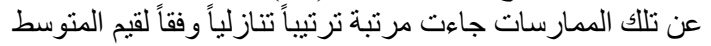

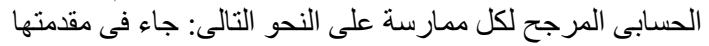

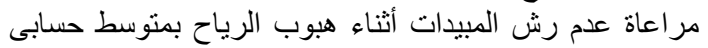

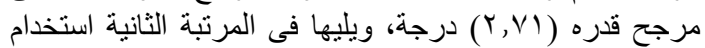

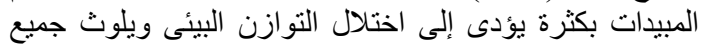

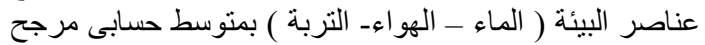

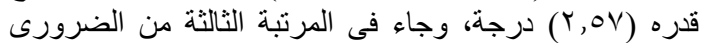

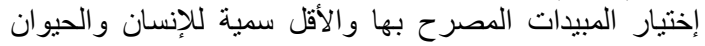

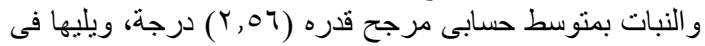
الأهمية بقية الممارسات على النحو المبين فى الجدول.

V- مستوى معرفة الزراع المبحوثين بممارسات إدارة وترشيد

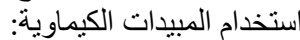

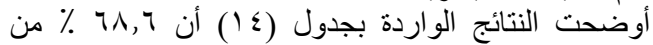

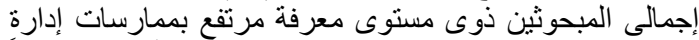

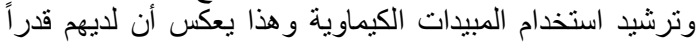

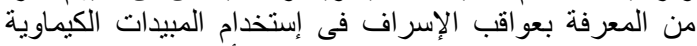

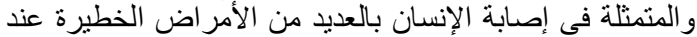

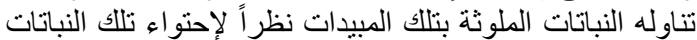

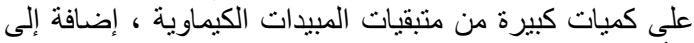

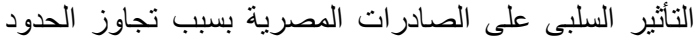

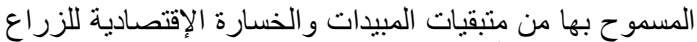

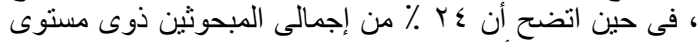

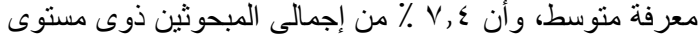

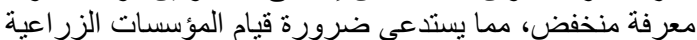

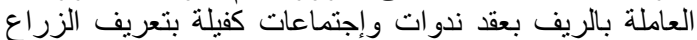
بعو اقب الإسراف في استخدام المبيدات الكيماوية على الإنسان

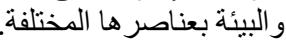

جدول (؛ () : :توزيع المبحوثين وفقاً لمستوى معرفتهم بمارسات إدارة وترشيد استخام المبيدات الكيماوية

\begin{tabular}{|c|c|c|}
\hline$\%$ & 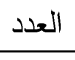 & مستوى المعرفة \\
\hline $\mathrm{V}, \varepsilon$ & 9 & منخفض (· (1-7 1) درجة \\
\hline$r \varepsilon, \cdot$ & $r q$ & متوسط (VI - r ) درجة \\
\hline $7 \Lambda, \uparrow$ & N & مرتفع (گ - - r ) درجة \\
\hline $1 \ldots$ & $|r|$ & الإجمالى \\
\hline
\end{tabular}

جدول (ه ) : التوزيع والنسبة المئوية للمبحوثين وفقاً لمعفتهم بممارسات إدارة وترشيد إستخدام المبيدات الكيماوية

\begin{tabular}{|c|c|c|c|c|c|c|c|c|}
\hline \multirow[t]{2}{*}{ الترتيب } & \multirow{2}{*}{ المتوسط الحسابى } & \multicolumn{2}{|c|}{ ل لا أعرف } & \multicolumn{2}{|c|}{ غير متأكد } & \multicolumn{2}{|c|}{ أعرف } & \multirow{2}{*}{ الكماروسات إدارة وترشيد استخدام المبيدات } \\
\hline & & $\%$ & العدد & $\%$ & العدد & $\%$ & |العدد & \\
\hline 1 & $r, Y)$ & $\varepsilon, 1$ & 0 & $r \cdot, Y$ & ro & $v_{0, r}$ & 91 & |ـ مر اعاة عدم رش المبيدات اثثاء هبوب الرياح | \\
\hline$r$ & r,OV & 11,7 & $1 \varepsilon$ & 19,1 & $r \varepsilon$ & $7 \Lambda, 7$ & $\Delta r$ & 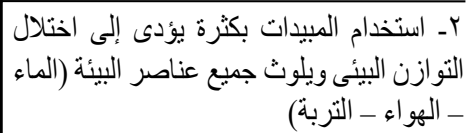 \\
\hline$r$ & $r, 07$ & $1 \cdot, 1$ & ir & $\overline{r, r}$ & $r V$ & 74,9 & $\lambda$ & 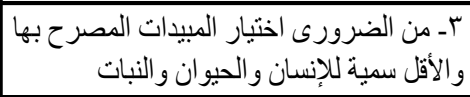 \\
\hline$\varepsilon$ & $r, 00$ & $\overline{1 r, r}$ & 17 & 19, & $r r$ & $T V, 1$ & $\overline{A r}$ & لأن- يفضل علم لمس المبيدات الكيماوية باليدا \\
\hline 0 & $r, 0 r$ & 17,0 & r. & $1 \leqslant, 9$ & 11 & $7 \Lambda, T$ & $\lambda r$ & لــــ من الضرورى إختبار المبيد المناسب \\
\hline 0 & r,OY & $10, \mathrm{~V}$ & 19 & 17,0 & $r$. & $T V, \lambda$ & Ar & 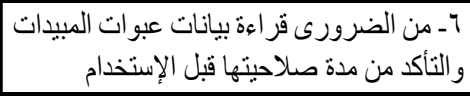 \\
\hline 7 & $r, 0$. & 11,7 & $1 \varepsilon$ & YY,\{ & rr & $\pi r, 0$ & vo & 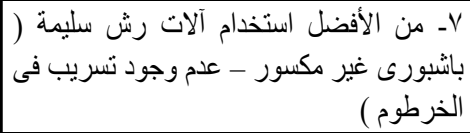 \\
\hline $\bar{v}$ & $r, \xi Y$ & $\overline{T V, r}$ & Y) & $\overline{1 \Lambda, Y}$ & rr & $T \leqslant, 0$ & $V \wedge$ & وجـ ضرورة ترك فترة سماح بين رش المبيد \\
\hline$\Lambda$ & $r, \S$ & $1 \leqslant, 9$ & 11 & $r \wedge, 9$ & ro & $07, r$ & 71 & 9ـ الإفراط فى استخدام المبيدات يقتل الأعداء \\
\hline 9 & $r, r Y$ & $r \cdot, r$ & To & $r 1,0$ & YY & $O r, A$ & $v^{\prime}$ & في حالة عطشاة عدم رش النباتات بالمبيدات وهى \\
\hline
\end{tabular}


وفى محاولة للوقوف على معرفة الزراع المبحوثين بكل

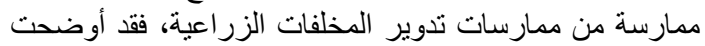

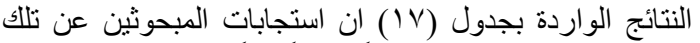

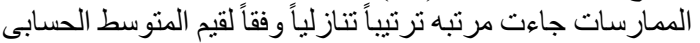

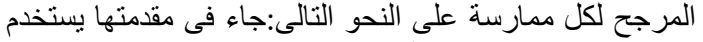

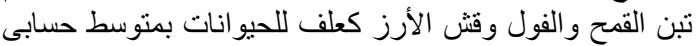

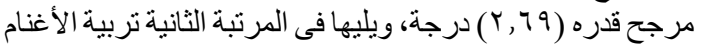

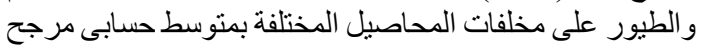

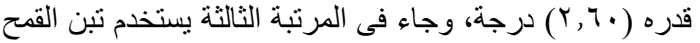

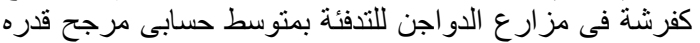

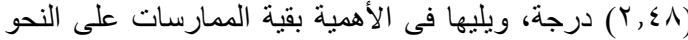

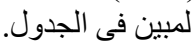

^ــ مستوى معرفة الزراع المبحوثين بممارسات تدوير المخلفات

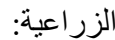

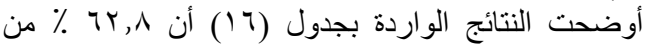

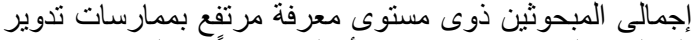

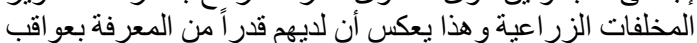

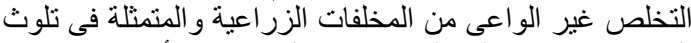

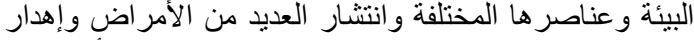

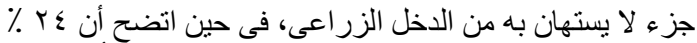

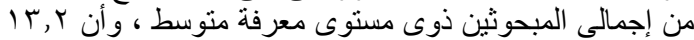

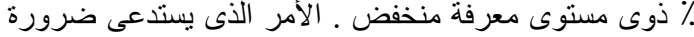

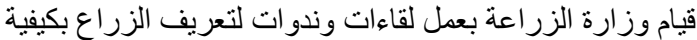

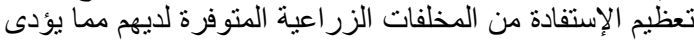

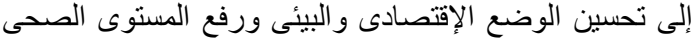
و الإجتماعى فى الريف المصن الإصىى.

جدول (7 1 ) :توزيع المبحوثين وفقاً لمستوى معرفتهم بممارسات تدوير المخلفات الزراعية

\begin{tabular}{|c|c|c|}
\hline$\%$ & 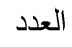 & مستوى المعرفة \\
\hline $1 r, r$ & 17 & منخفض ( • (-7 1) درجة \\
\hline$r \leqslant, \cdot$ & rq & متو سط (V - V س ) درجة \\
\hline 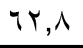 & $v_{7}$ & 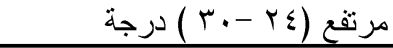 \\
\hline $1 \ldots$ & $|r|$ & الإجمالى \\
\hline
\end{tabular}

جدول (V V) : التوزيع والنسبة المئوية للمبحوثين وفقاً لمعرفتهم بممارسات تدوير المخلفات الزراعية

\begin{tabular}{|c|c|c|c|c|c|c|c|c|}
\hline \multirow[t]{2}{*}{ الترتيب } & \multirow{2}{*}{ المتوسط الحسابى } & \multicolumn{2}{|c|}{ لا أعرف } & \multicolumn{2}{|c|}{ غير متأكد } & \multicolumn{2}{|c|}{ أعرف } & \multirow[t]{2}{*}{ ممارسات تدوير المخلفات الزراعية } \\
\hline & & $\%$ & العدد & $\%$ & العدد & $\%$ & العدد & \\
\hline 1 & $r, 79$ & 7,7 & $\Lambda$ & $I V, \varepsilon$ & r) & $V Y$, & $9 r$ & للحيو يستخدم تبن القمح و الفول وفش الأرز كعلف \\
\hline$r$ & $r, T$. & 9,1 & 11 & $r r, r$ & TV & 71,7 & $\overline{\lambda \mu}$ & الم-ــتربية الأغنام و الطيور على مخلفات \\
\hline$r$ & $r, \leqslant \Lambda$ & $1 \leqslant, 9$ & 11 & $T r, r$ & TV & $\pi, \Lambda$ & $V_{1}$ & لآــ يستخدم تبن القمح كفرشة فى مز ارع الدو اجن \\
\hline$\varepsilon$ & $r, \varepsilon \varepsilon$ & $\mid V, \varepsilon$ & $r 1$ & $r 1,0$ & rq & 71,1 & $V \varepsilon$ & السماد العضوى عروش وبقايا المحاصبل فى صناعة \\
\hline 0 & $r, r q$ & $r \cdot, r$ & ro & 19,1 & $T \leq$ & 09,0 & $V Y$ & 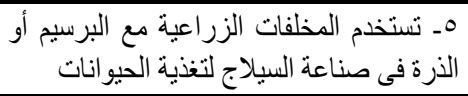 \\
\hline 7 & $r, Y \xi$ & $r V, r$ & rr & $r 1,0$ & KY & $01, r$ & $\pi$ & 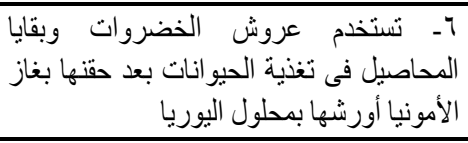 \\
\hline $\bar{v}$ & $r, Y T$ & $r \bar{r}$ & $r r$ & $r \varepsilon,$. & rq & $\sum 9,7$ & 7. & من الصقيع ميتخ قش الأرز لحماية الشتلات الصغيرة \\
\hline$\Lambda$ & $r, Y_{1}$ & $r_{1, \varepsilon}$ & $r \Lambda$ & $10, V$ & 19 & Or, & $7 \leq$ & أخرى يستخدم قش الأرز كبيئة زراعية لمحاصيل \\
\hline 9 & $r, 11$ & $r_{0,0}$ & $\varepsilon r$ & $1 \Lambda, Y$ & Kr & $\sum \neg, r$ & 01 & 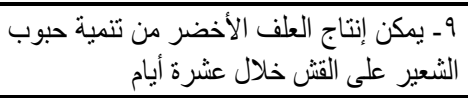 \\
\hline 1. & $r, \cdot r$ & $r v, r$ & $\leqslant 0$ & $r r, 1$ & rA & $r q, v$ & $\varepsilon \Lambda$ & 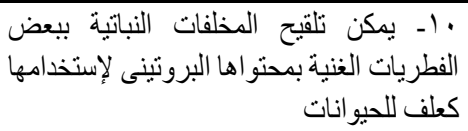 \\
\hline
\end{tabular}

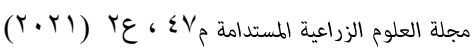


و الإجر اءات الر امبة إلى تحقيق ذللك ومن ثم يمكن الحصول على بيئة نظيفة و غذاء آمن وصحئ إلى نهيق.

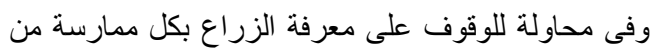

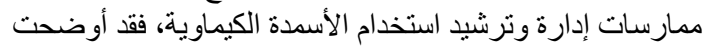

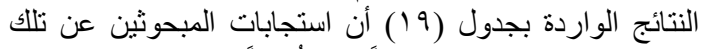

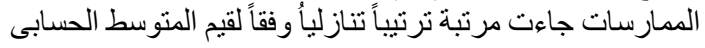

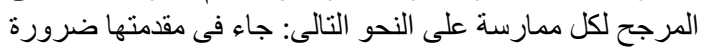

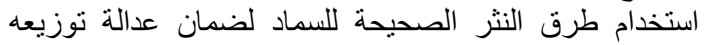

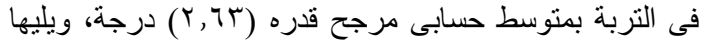

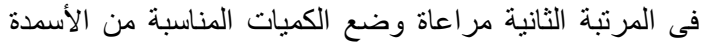

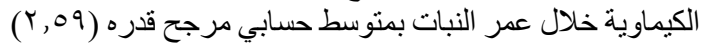

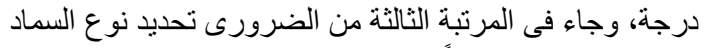

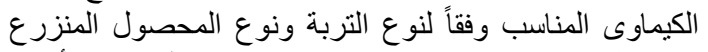

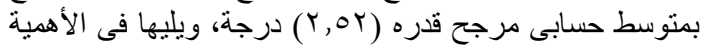
بقية الممارسات على النحو المبين فى الجدول
9- مستوى معرفة الزراع المبحوثين بممارسات إدارة وترشيد

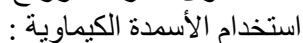

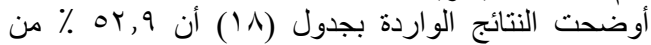

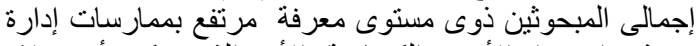

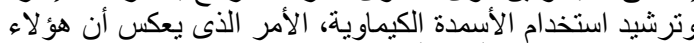

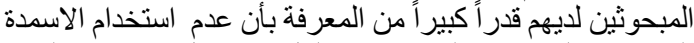

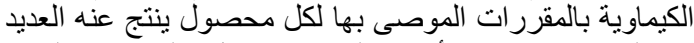

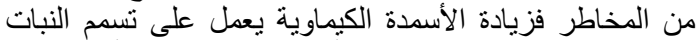

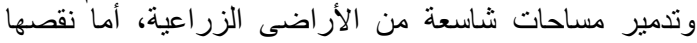

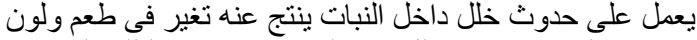

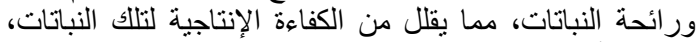

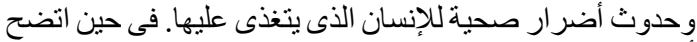

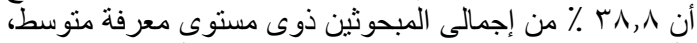

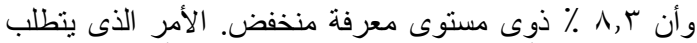

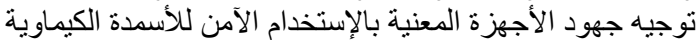

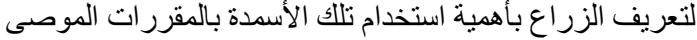

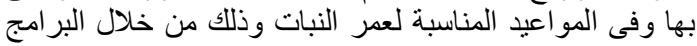

جدول (^ ا ): توزيع المبحوثين وفقاً لمستوى معرفتهم بممارسات إدارة وترشيد إستخدام الأسمدة الكيماوية

\begin{tabular}{|c|c|c|}
\hline$\%$ & 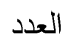 & مستوى المعرفة \\
\hline$\wedge, r$ & 1. & منخفض (· (1- 1) درجة \\
\hline$\mu \wedge, \wedge$ & $\varepsilon V$ & منوسط (V - س r ) درجة \\
\hline or, 9 & $7 \leq$ & مرتفع (乏 ب -.ب ) درجة \\
\hline
\end{tabular}

جدول (9 1) :التوزيع والنسبة المئوية للمبحوثين وفقاً لمعرفتهم بممارسات إدارة وترشيد استخدام الأسمدة الكيماوية

\begin{tabular}{|c|c|c|c|c|c|c|c|c|}
\hline \multirow[t]{2}{*}{ التزتيب } & \multirow{2}{*}{ المتوسط الحسابى } & \multicolumn{2}{|c|}{ لا أعرف } & \multicolumn{2}{|c|}{ غير متأكد } & \multicolumn{2}{|c|}{ أعزف } & \multirow{2}{*}{ الكيمارية إدارة وترشيد استخدام الأسمدة } \\
\hline & & $\%$ & العدد & $\%$ & العدد & $\%$ & العدد & \\
\hline 1 & r,Tr & 9,1 & 11 & 19, & rr & $v 1, q$ & AV & 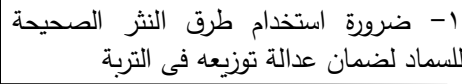 \\
\hline r & $r, 09$ & 9,1 & 11 & $r r, 1$ & r^ & $T V, \Lambda$ & Ar & 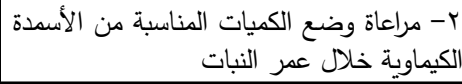 \\
\hline$r$ & r,or & $1 \cdot, v$ & ir & $r \uparrow, 0$ & rr & $T r, \Lambda$ & $V Y$ & 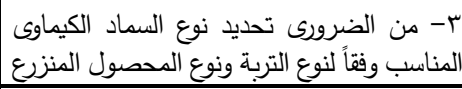 \\
\hline$\varepsilon$ & $Y, \leqslant V$ & $1 \leqslant, 9$ & 11 & $r r, l$ & rA & $T r,$. & vo & الموصى بها لكل من الضروى الإلتزام بالمقررات السمادية \\
\hline 0 & $r, \varepsilon r$ & $1 \leqslant, 9$ & 11 & $r \wedge, 1$ & $r \varepsilon$ & ov, & 79 & الموثوق فرورة شراء الأسمدة الكيماوية من الدصادر \\
\hline 7 & r, r. & $10, \mathrm{~V}$ & 19 & q & $\varepsilon 1$ & $0 ., \varepsilon$ & 71 & تؤدى لكبرورة تجنب الثمار بصتخدام الهرمونات التى عير عادية \\
\hline v & $r, r$. & $r \varepsilon,$. & rq & $r, r$ & rV & or,, & 70 & V- مراعاة وضع الأسمدة الكيماوية على الشراقى \\
\hline$\wedge$ & $r, r \wedge$ & 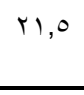 & rT & $r \wedge, q$ & ro & $\varepsilon 9,7$ & 7. & خ خاصة لمحورة عدم الإكثار من التسميد الأزوتى \\
\hline 9 & 1,99 & $r \wedge, q$ & ro & $\varepsilon r$, & or & YA, & $\Gamma \varepsilon$ & 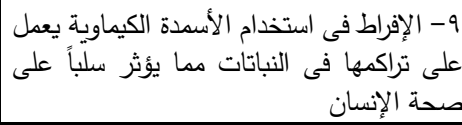 \\
\hline 1. & 1,91 & rr, & rq & ґА, & $\varepsilon 7$ & $r ৭, \wedge$ & ז & أى رطوبة اعاة تخزين الأسمدة الكيماوية بعيداً عن \\
\hline
\end{tabular}

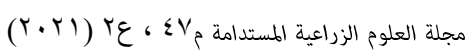




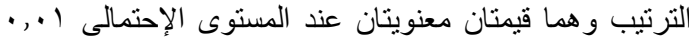

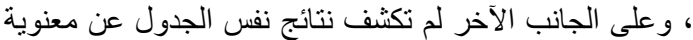

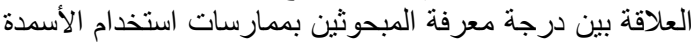

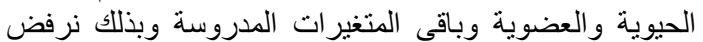

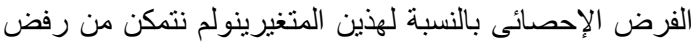

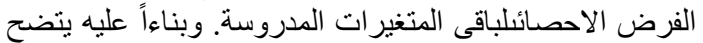

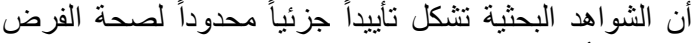

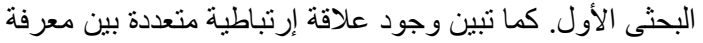

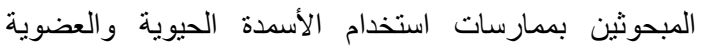

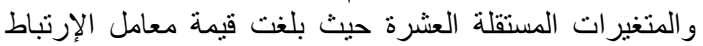

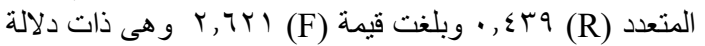

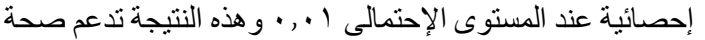

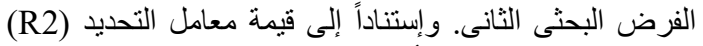

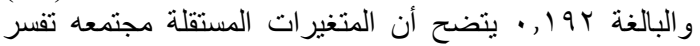

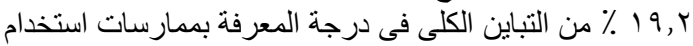

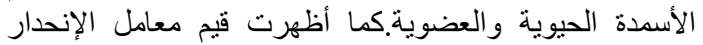

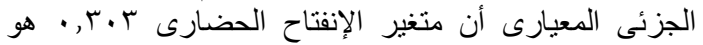

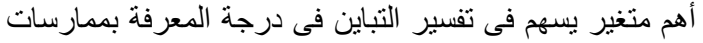

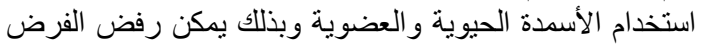

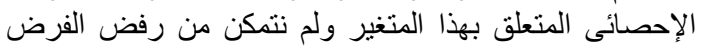

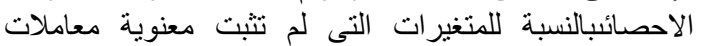

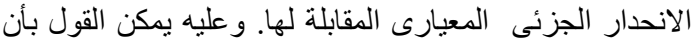

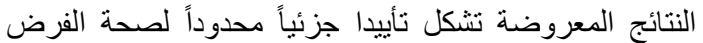

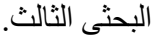

وفى محاولة للوقوف على أكثر المتغير ات المستقلة تأثثراً على الإنى

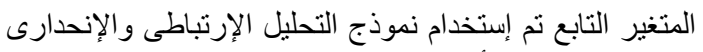

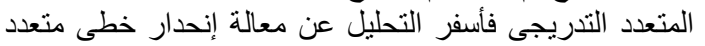

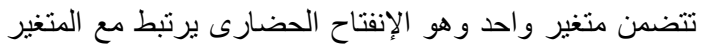

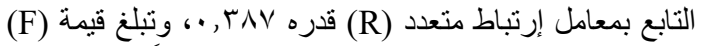

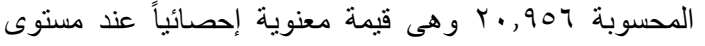

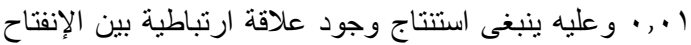

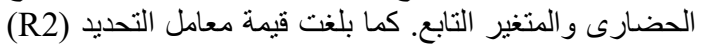

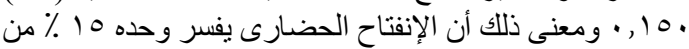

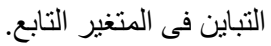

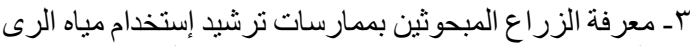

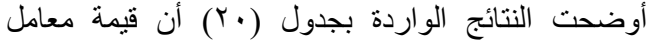

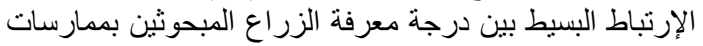

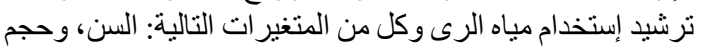

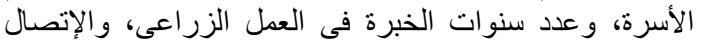

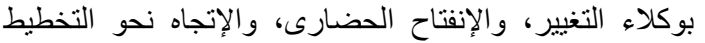

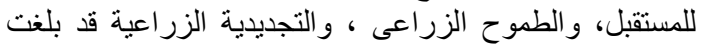

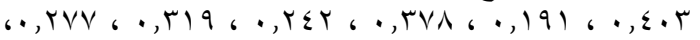

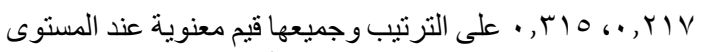

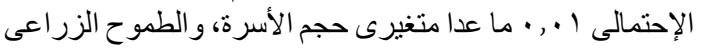

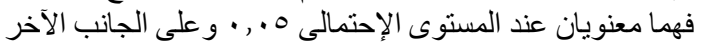

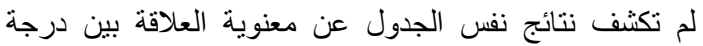

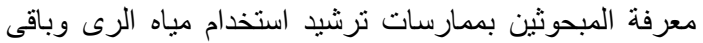

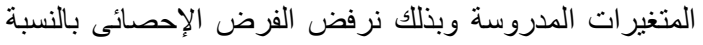

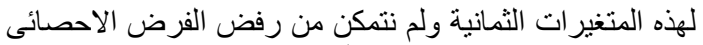

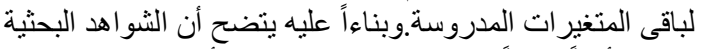

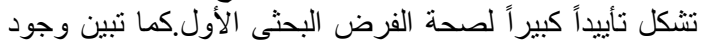

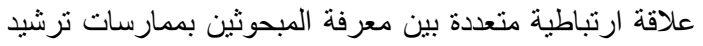

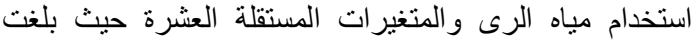

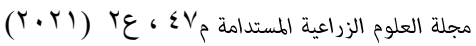

ثالثا: العلاقات الإرتباطية والإنحدارية بين المتغيرات المستقلة

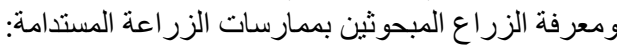
اـ معرفة الزراع المبحوثين بممارسات الحفاظ على مياه الرى لئ أوضحت النتائج الواردة بجدول ( • Y) أن قيمة معامل الإرتباط

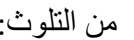

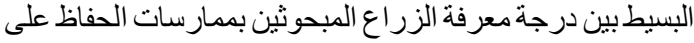

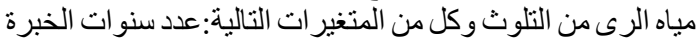

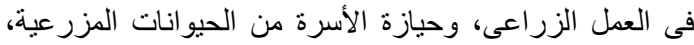

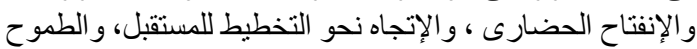

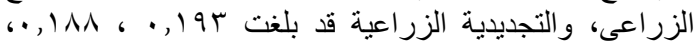

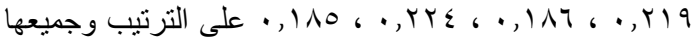

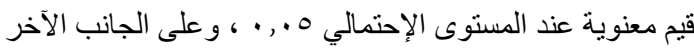

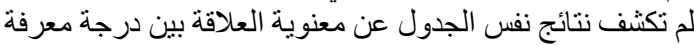

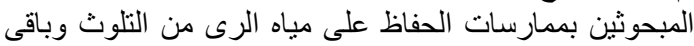

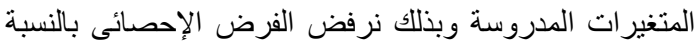

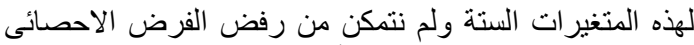

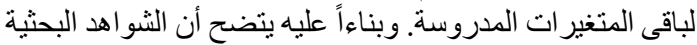

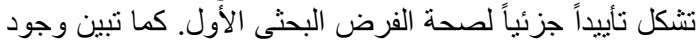

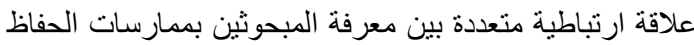

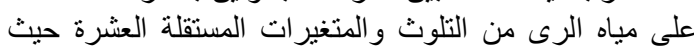

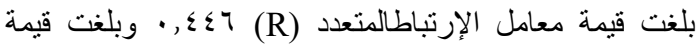

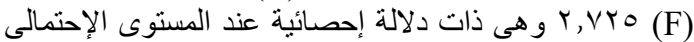

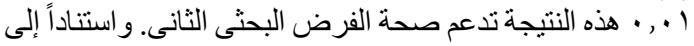

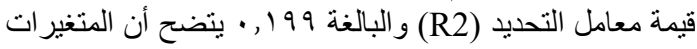

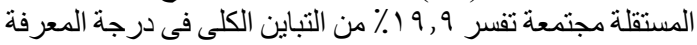

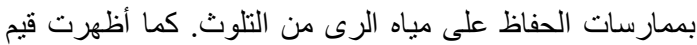

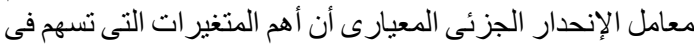

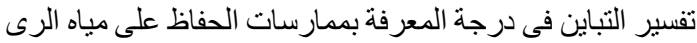

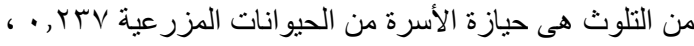

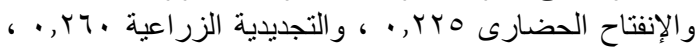

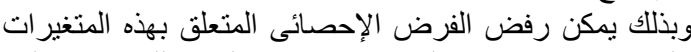

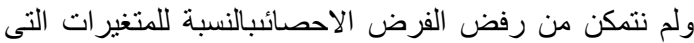

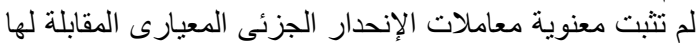
ـ و وعليه يمكن القول بأن النتائج المعروضة الجزئ تثكل تأييداً جزئياً محدوداً لصحة الفرض البحثى الثنالث.

وفى محاولة للوقوف على أكثر المتغيرات المستقلة تأثير ألتا

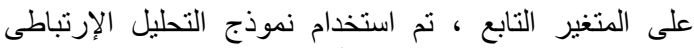

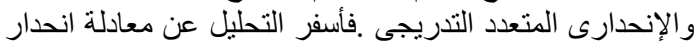

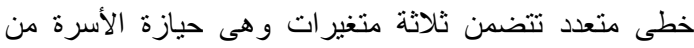

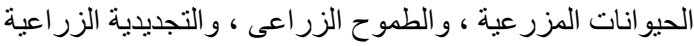

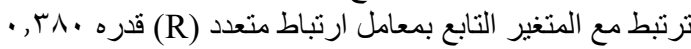

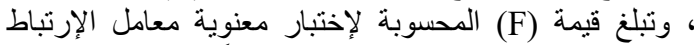

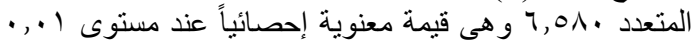

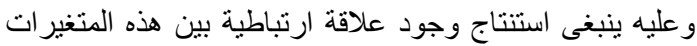

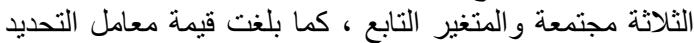

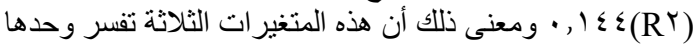

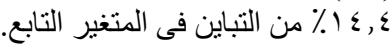

r- معرفة الزراع المبحوثين بممارسات استخدام الأسمدة الحيوية

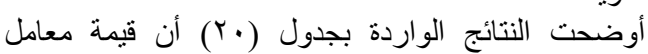

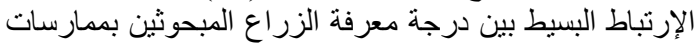

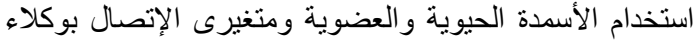

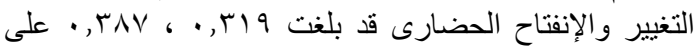




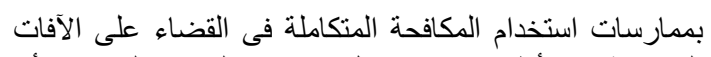

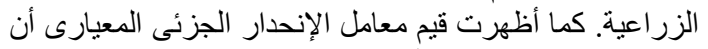

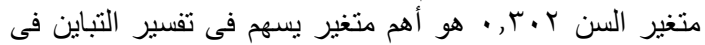

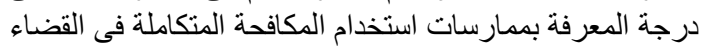

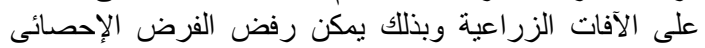

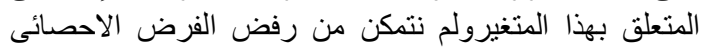

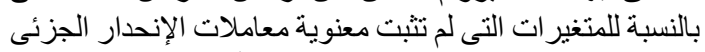

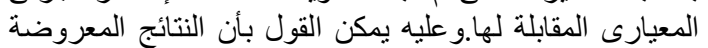
تنثكل تأييداً جزئياً محدوداً لصحة الفرض البحثى الثالث.

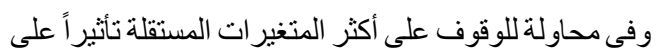
التنغير التابع تم استخدام نموذج التحليل الإرتباطى والإنى الإنحدارى

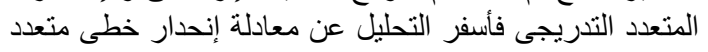

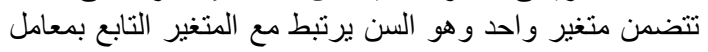

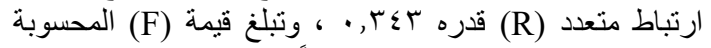

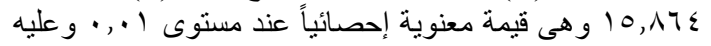
ينبغى استنتاج وجود علاقة إرتباطية بين السن و المتغير التنابع. كما

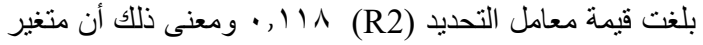
السن يفسر وحده ^, 11 1 ٪ من التباين فى المتغير الثنابع

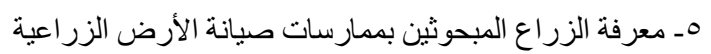

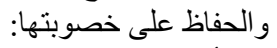
أوضحت النتائج الو اردة بجدول (· · أن أن قيمة معامل الإرتباط

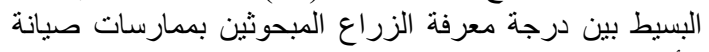

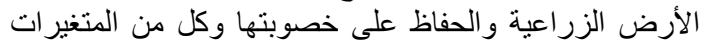

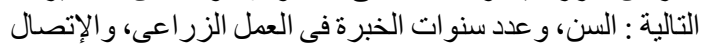

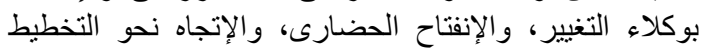

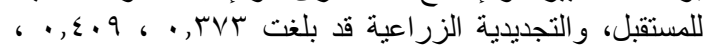

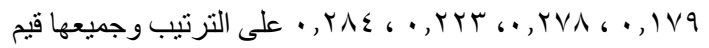

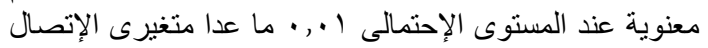
بو كلاء التغيير، والإتجاه نحو التخطيط للمستقبل فئل فهما معنويان الإنصان

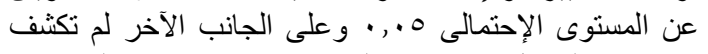

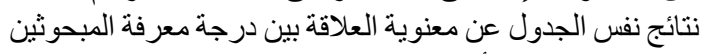

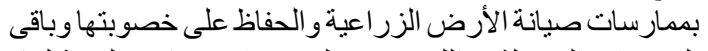

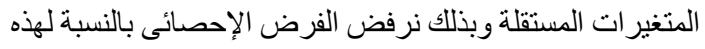

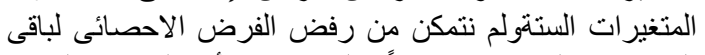

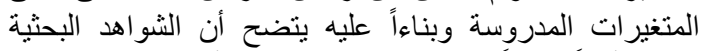

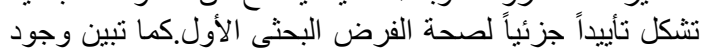

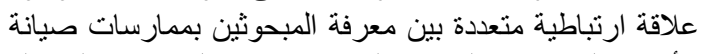

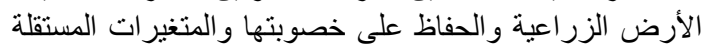

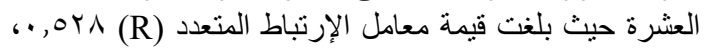

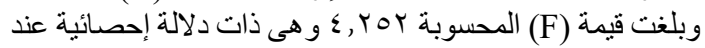

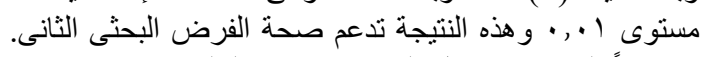

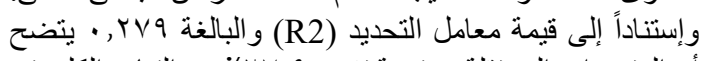

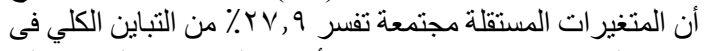

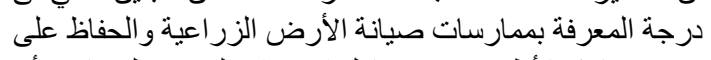

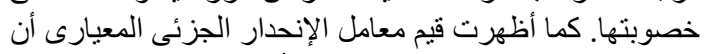

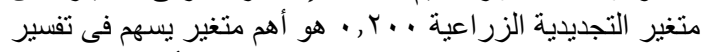

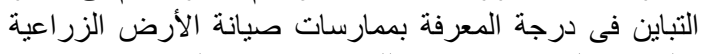

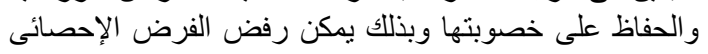

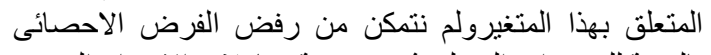
بالنسبة للمتغيرات التى لم تثبت معنوية معاملات الإنحدار الجزئى الإنى

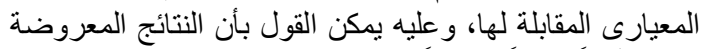

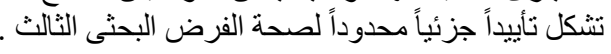

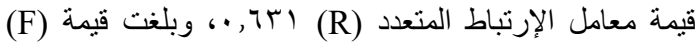

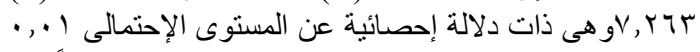

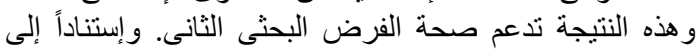

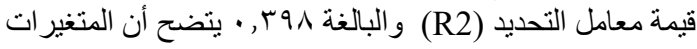

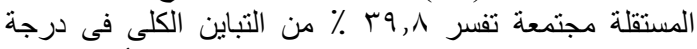

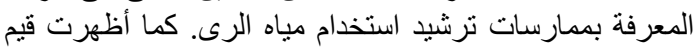

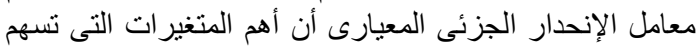

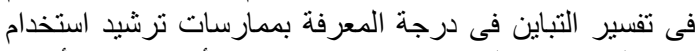

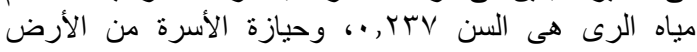

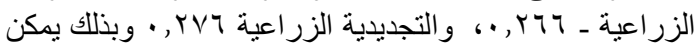

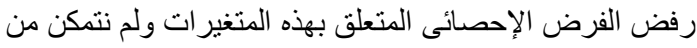

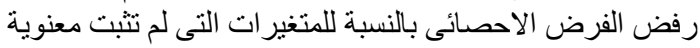

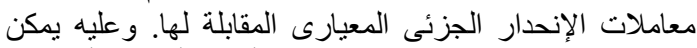

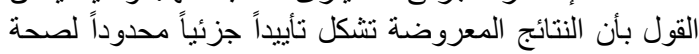
الفرض البحثى الثنالث. - الثرو

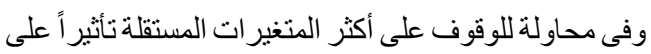

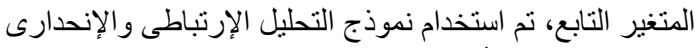

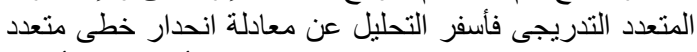

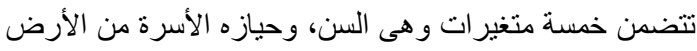

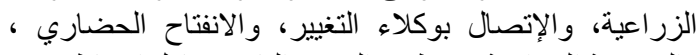

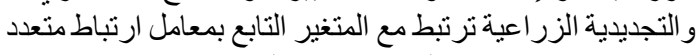

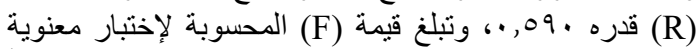

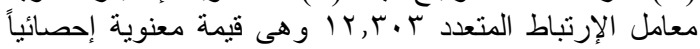

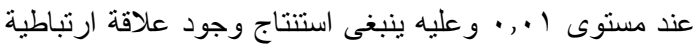

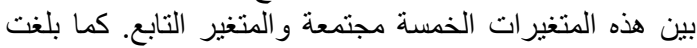

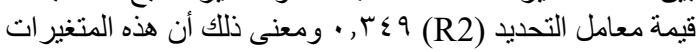

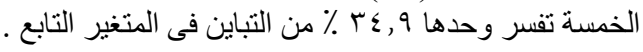

ــ معرفة الزراع المبحوثين بممارسات استخدام المكافحة الكتكاملة فى القضاء على الآفات الزر اعبية

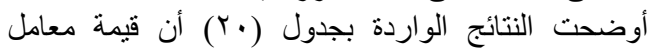
الإرتباط البسيط بين درجة معرفة الزراع الزعاع المبحوثين بممارسات

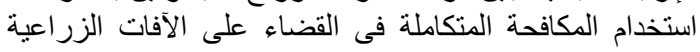

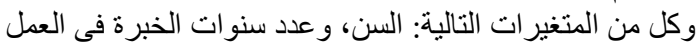

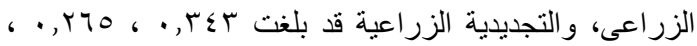

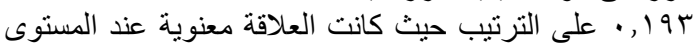

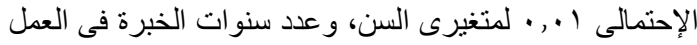

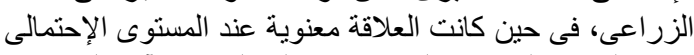

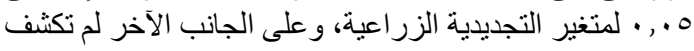

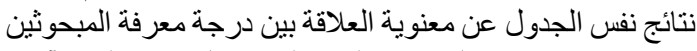

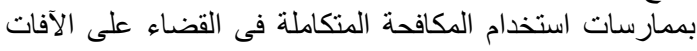

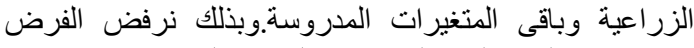

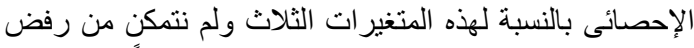

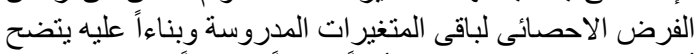

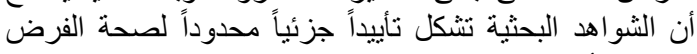

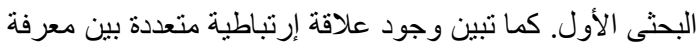

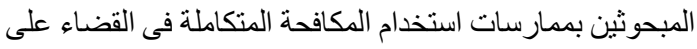

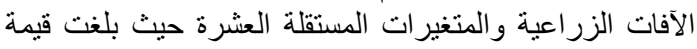

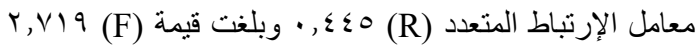

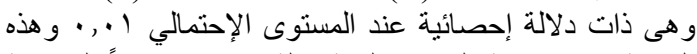

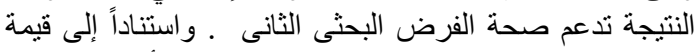

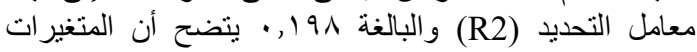

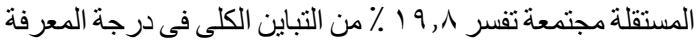


هذين المتغيرين و المتغير التابع.كما بلغت قيمة معامل التحديد

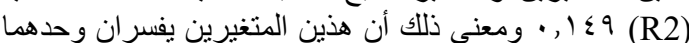

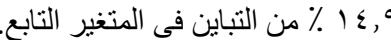

V- معرفة الزراع المبحوثين بممارسات إدارة وترشيد استخدام

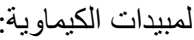

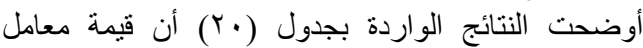
الإرتباط البسيط بين درجة معرفة الزراع المباع المبحوثين بممارسات

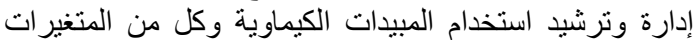

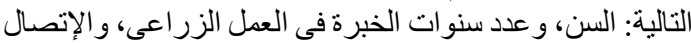

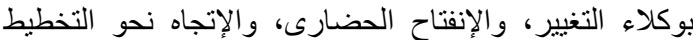

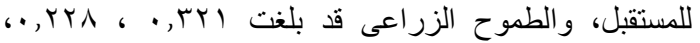

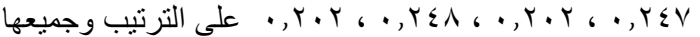

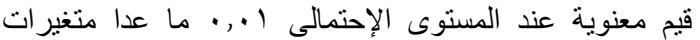

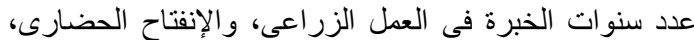

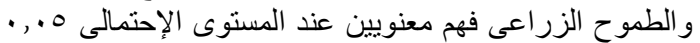

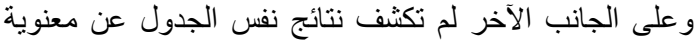

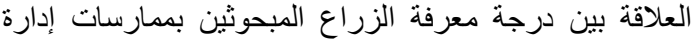

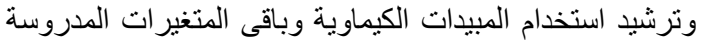

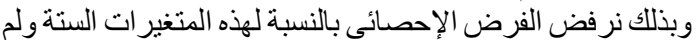

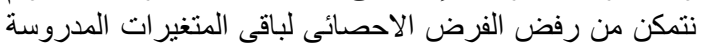

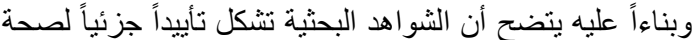

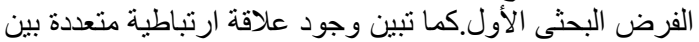

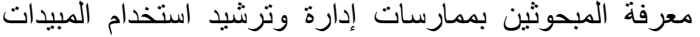

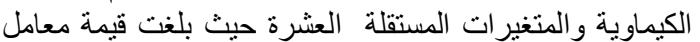

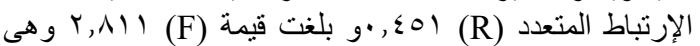

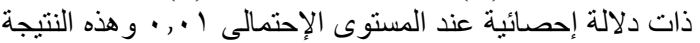

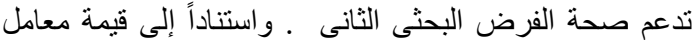

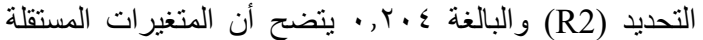

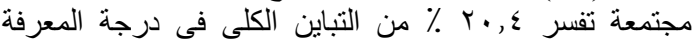

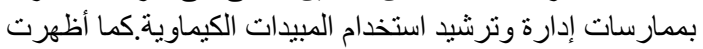

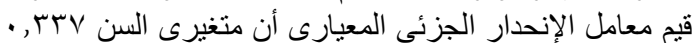

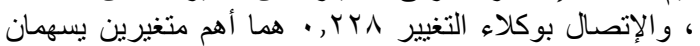

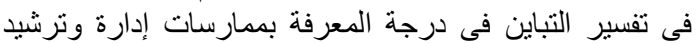

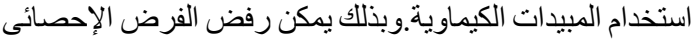

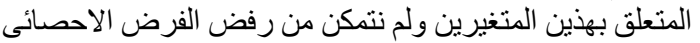

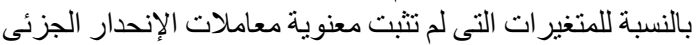

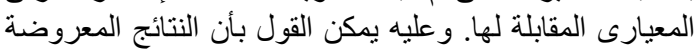

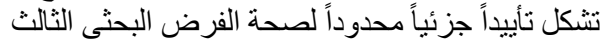

وفى محاولة للوقوف على أكثر المتغير ات المستقلة تأثير اً على الإنى المتغير التابع، نم استخدام نموذج التحليل الإرتباطى و الإنحدارى التحني

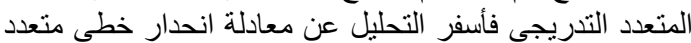

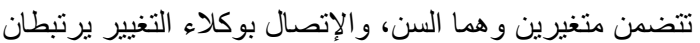

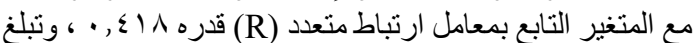

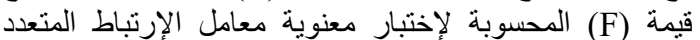

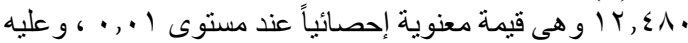

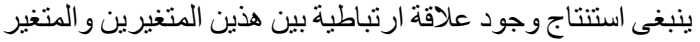

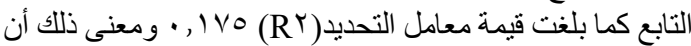

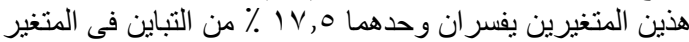

^ـ معرفة الزراع المبحوثين بممارسات تدوبر المخلفات

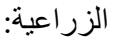

أوضحت النتائج الواردة بجدول (†) (†) أن قيمة معامل الإرتباط البسيط بين درجة معرفة الزر اع المبحوثين بممارسات

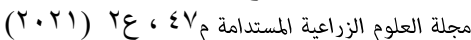

وفى محاولة للوقوف على أكثر المتغيرات المستقلة تأثيراً

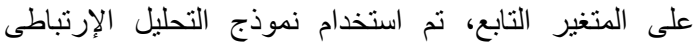

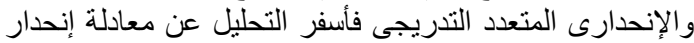

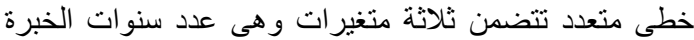

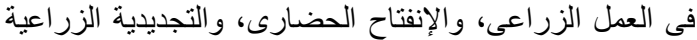

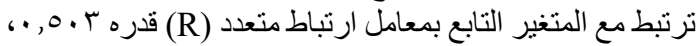

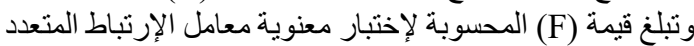

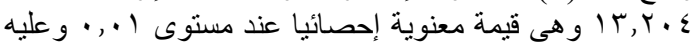

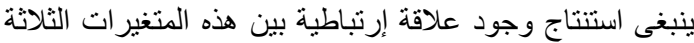

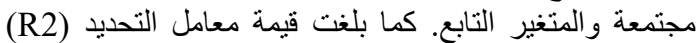

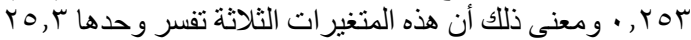

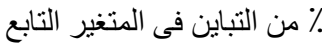

7- ـمعرفة الزراع المبحوثين بممارسات زراعة الأصناف المحسنة و التتو ع المحصولى الرعي: أوضحت النتائج الواردة بجدول (ب) (Y) أن قيمة معامل الإرنباط

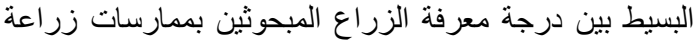

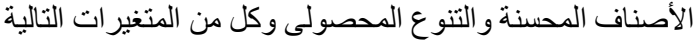

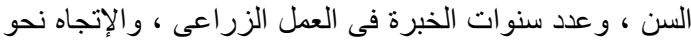

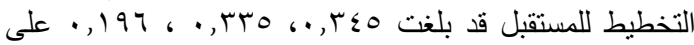

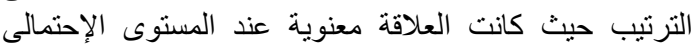

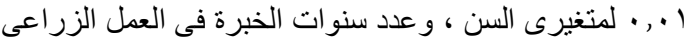

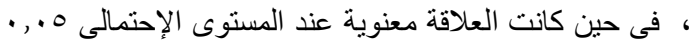

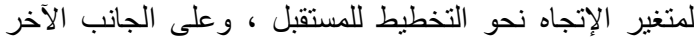

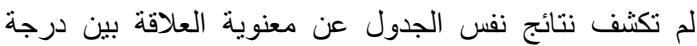

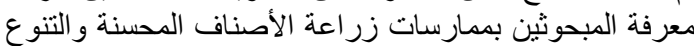

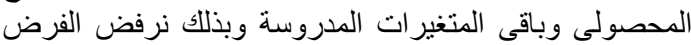

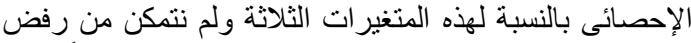

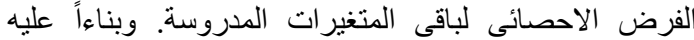

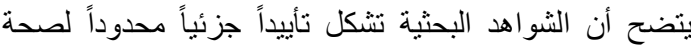

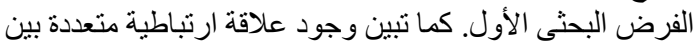

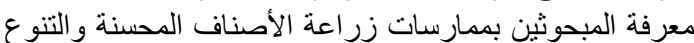

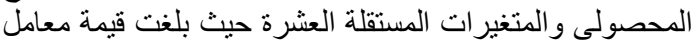

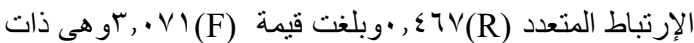

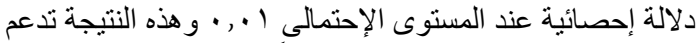

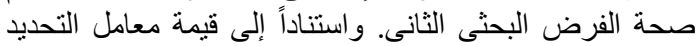

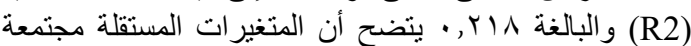

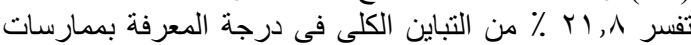

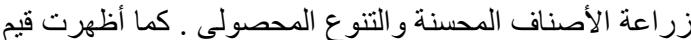

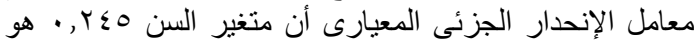

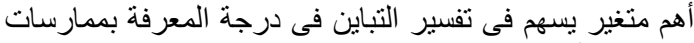

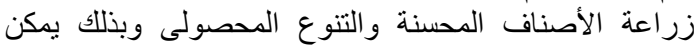

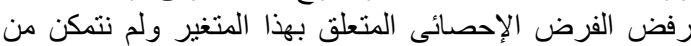

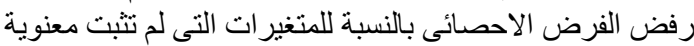

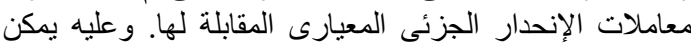

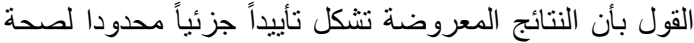
الفرض البحثى الثالث الث الثعرو

وفى محاولة للوقوف على أكثر المتغير ات المستقلة تأثبر اً على إنى

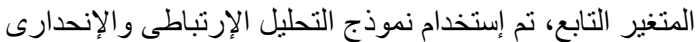

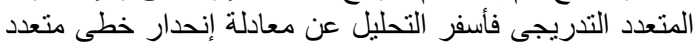

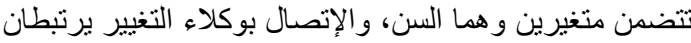

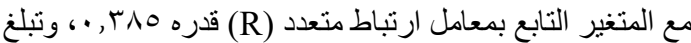

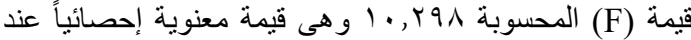

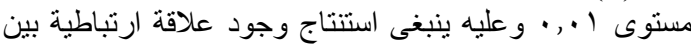


متعددة بين معرفة المبحوثين بممارسات إدارة وترشيد استخدام

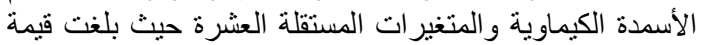

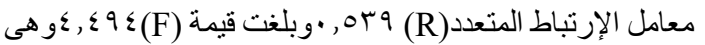

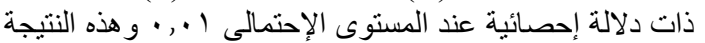

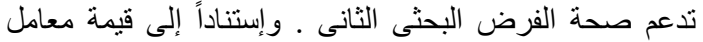

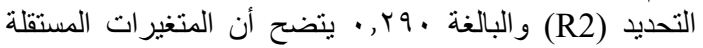

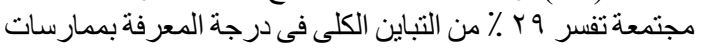

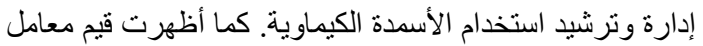

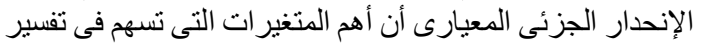

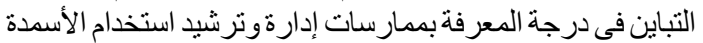

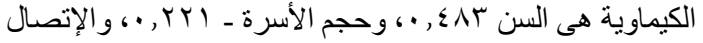

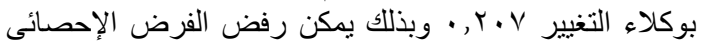

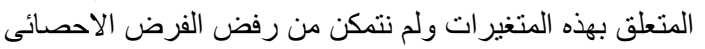

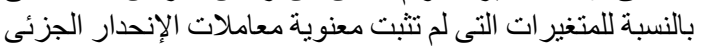

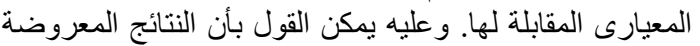

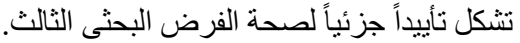

وفى محاولة للوقوف على أكثر المتغير ات المستقلة تأثير اً على الإنى

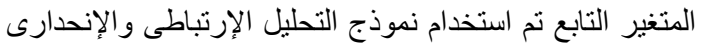

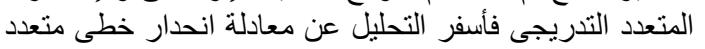

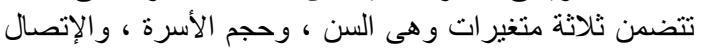

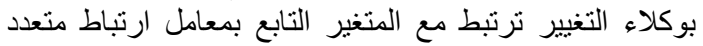

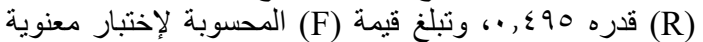

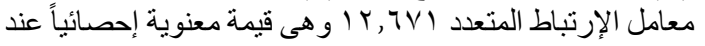

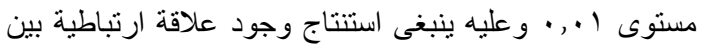

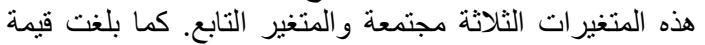

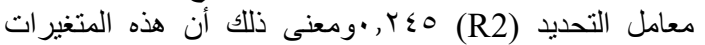

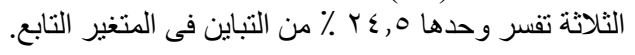

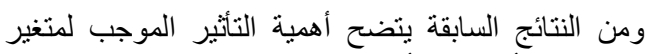

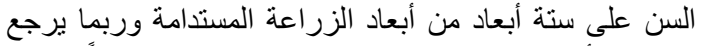

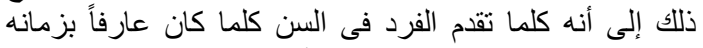

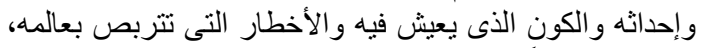

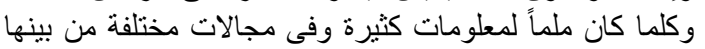

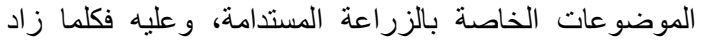

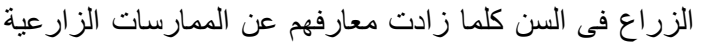

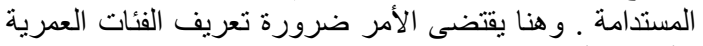

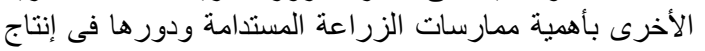

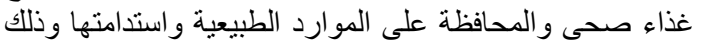

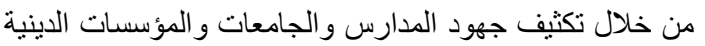
و الإجتماعية ووسائل الإعلام المختلفة وتضافر ها في هذات المئ الثأن.

كما أوضحت النتائج أهمية التأثير الموجب لمتغير الإتصال

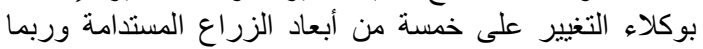

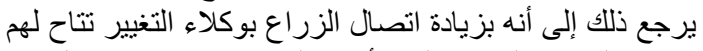

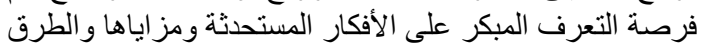

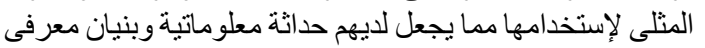

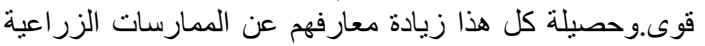

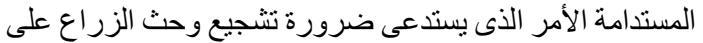
الإتصال المستمر بوكلاء التغيير.

كما أوضحت النتائج أهمية التأثثر الموجب لمتنغيرى التجديدية

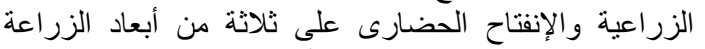

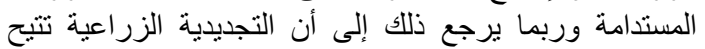

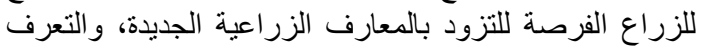
على الخبرات الزر اعية المختلفة وكل ما هو جديد فلى هذا المية المجال

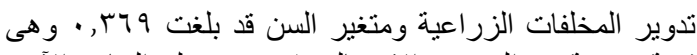

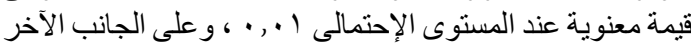

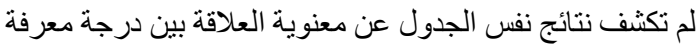

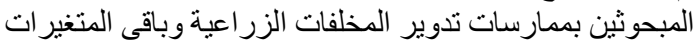

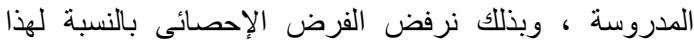

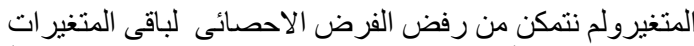

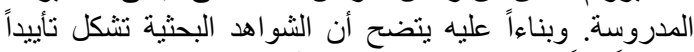

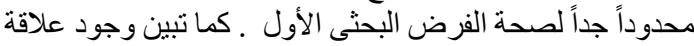

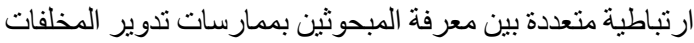

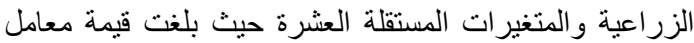

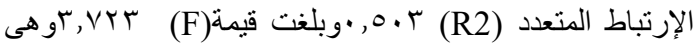

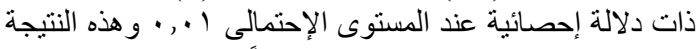

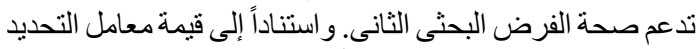

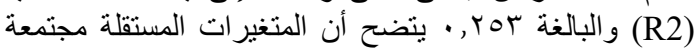

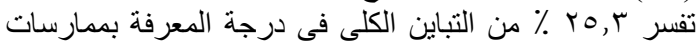

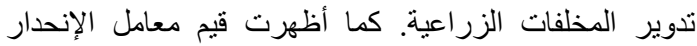

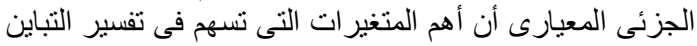

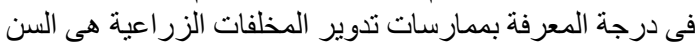

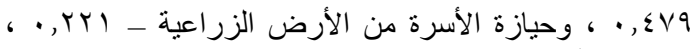

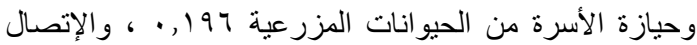

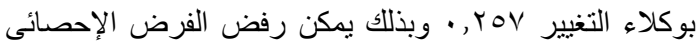

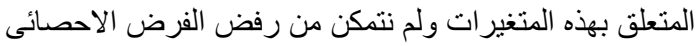

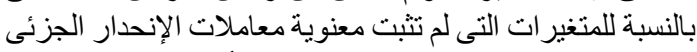

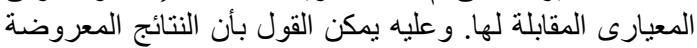
تشكل تأييداً جزئياً لصحة الفرض و ليه بيكن البحثى الثالث.

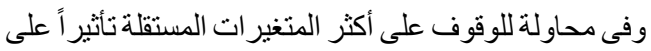

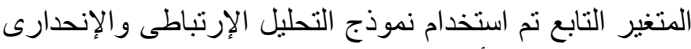

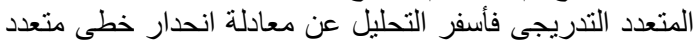

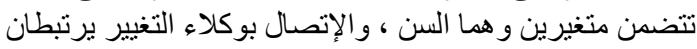

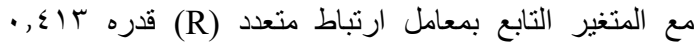

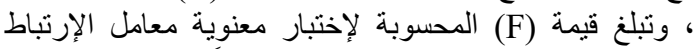

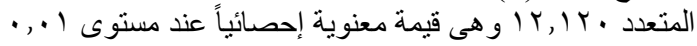

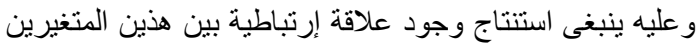

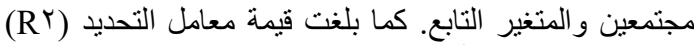

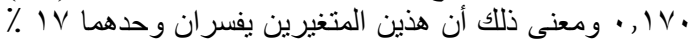
من التباين فى المتغير التابع.

9ـ معرفة الزراع المبحوثين بممارسات إدارة وترشيد استخدام

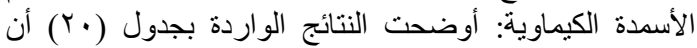

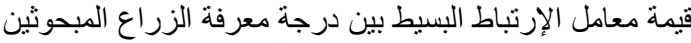

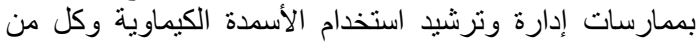

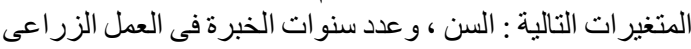

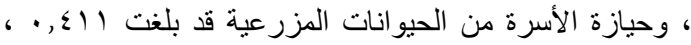

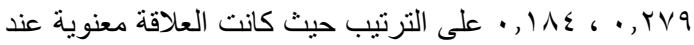

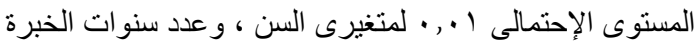

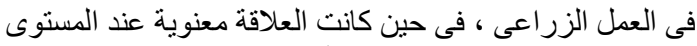

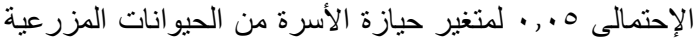

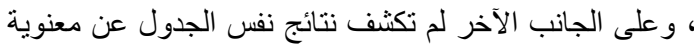

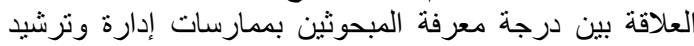

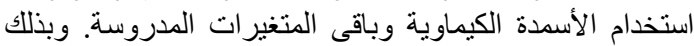

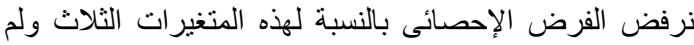

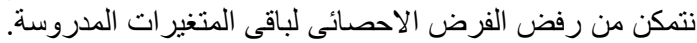

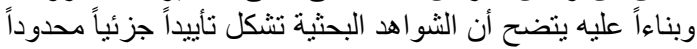

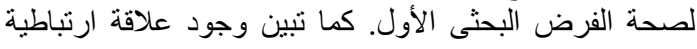

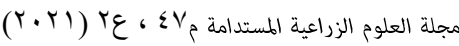


على خصوبتها، وزر اعة الأصناف المحسنة و التنوع المحصولى المئي

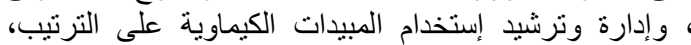

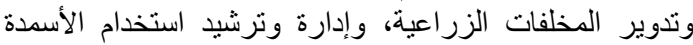

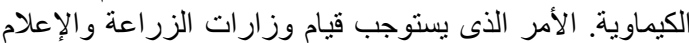

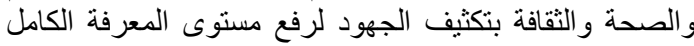

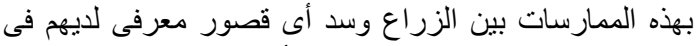

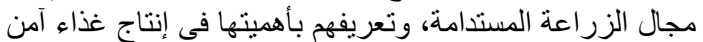

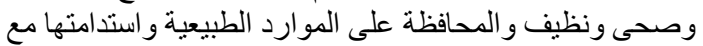
تعزيز ثقافة ترشيد هذه المو ارد وذللك من خلال:

(أ) إثر اكهم فى بر امج وندو ات ودور ات تدريبية فعالة و هادفة إلى الى الإن

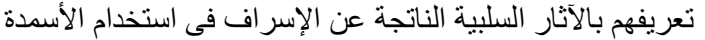

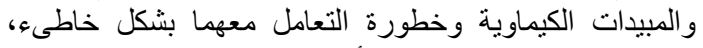

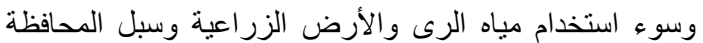

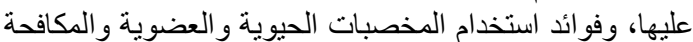
المتكاملة فى القضاء على الآفات الزراعية وزراعة العية الأصناف

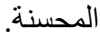

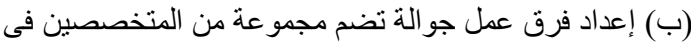

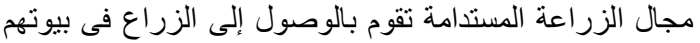

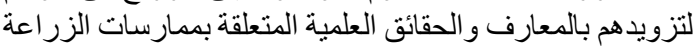

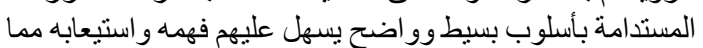
بساعد فى نشر المعرفة عن تلألك الممارسات.

(ج) قبام المنظمات الزراعية الريفية برحلات علمية لتبصير

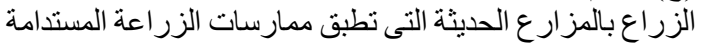

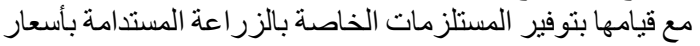

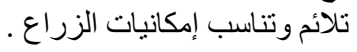

(د) أن يلحق بمكتب المرشد الزراعى جهاز كمبيوتر وانترنت

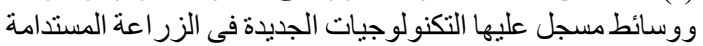
لتبصير الزراع مبهائ.

(هـ) تقديم المزيد من التجارب العلمية الناجحة لإستخدام التوصيات المقدمة من جهات البحث العلمى فى هذا المجال.
مما يؤدى إلى إثراء معارفهم وخبر اتهم عن الممارسات الزر اعية

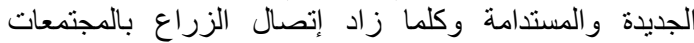

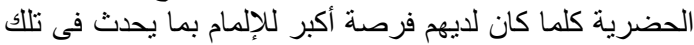

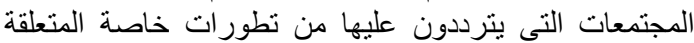

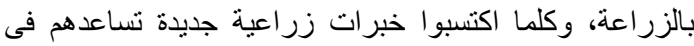

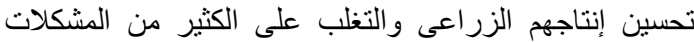

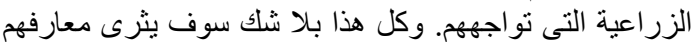

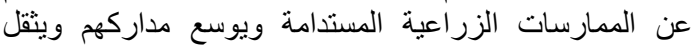

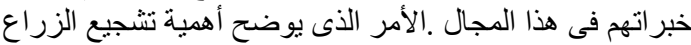

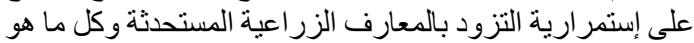

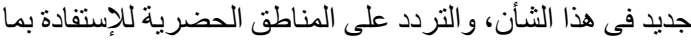
فيها من إنجاز ات وخبرات في هذات هذا المجال.

التوصيات

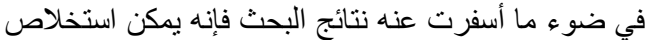

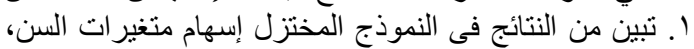

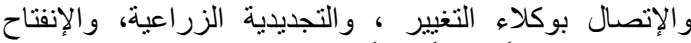

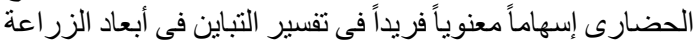

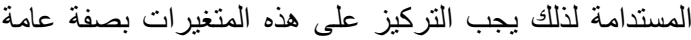

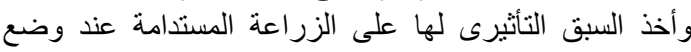

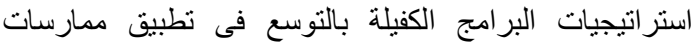

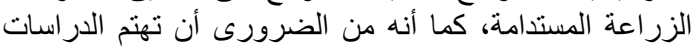

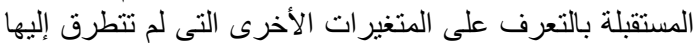

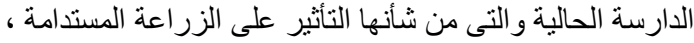

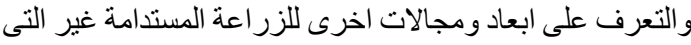
تم تناولها في هذه الدر اسة.

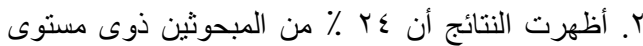

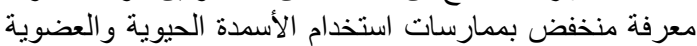

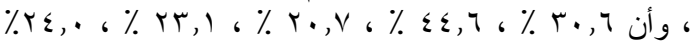

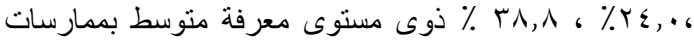

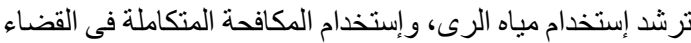

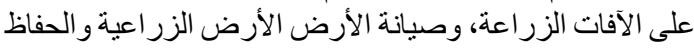

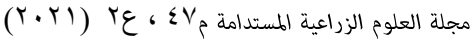




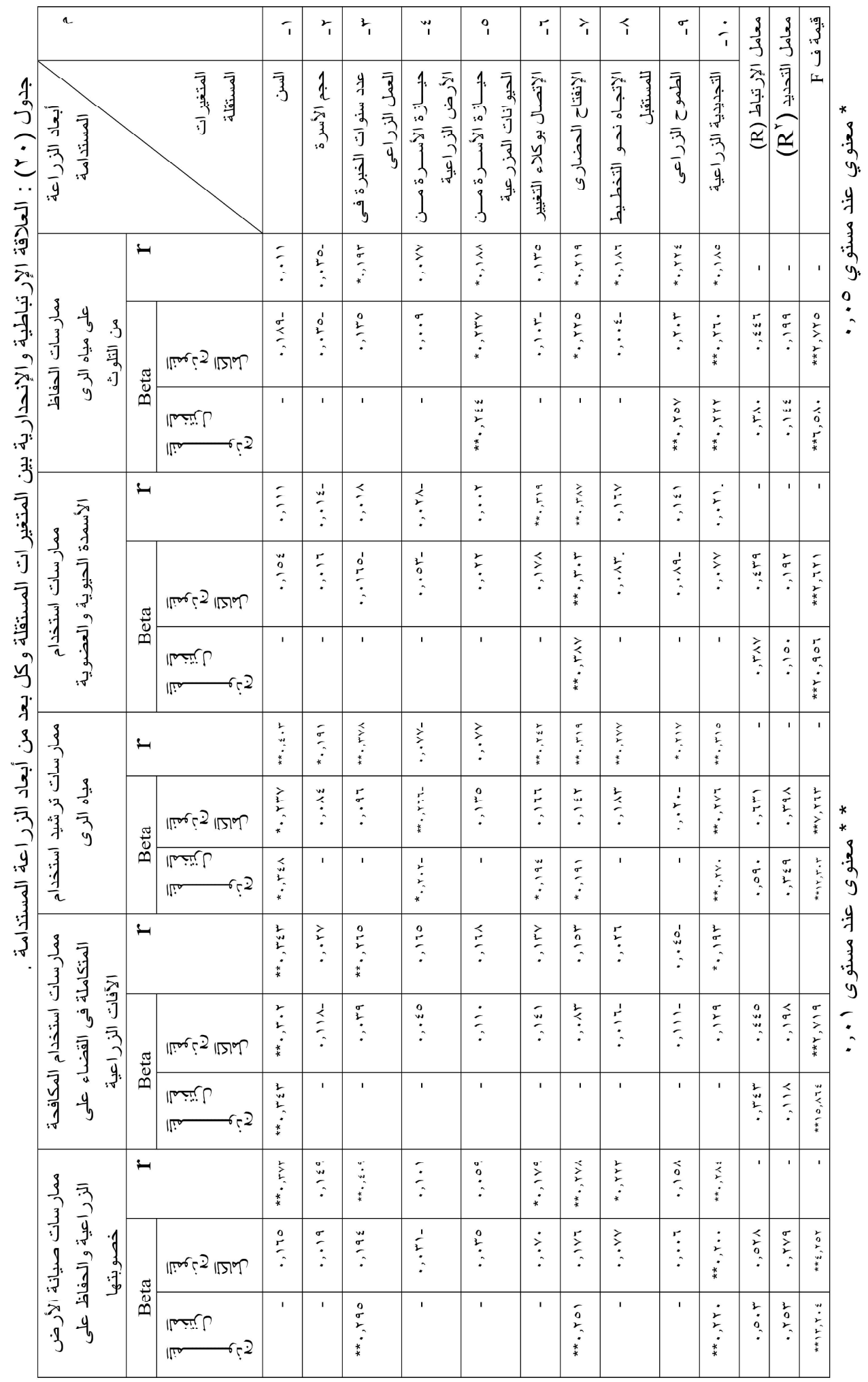




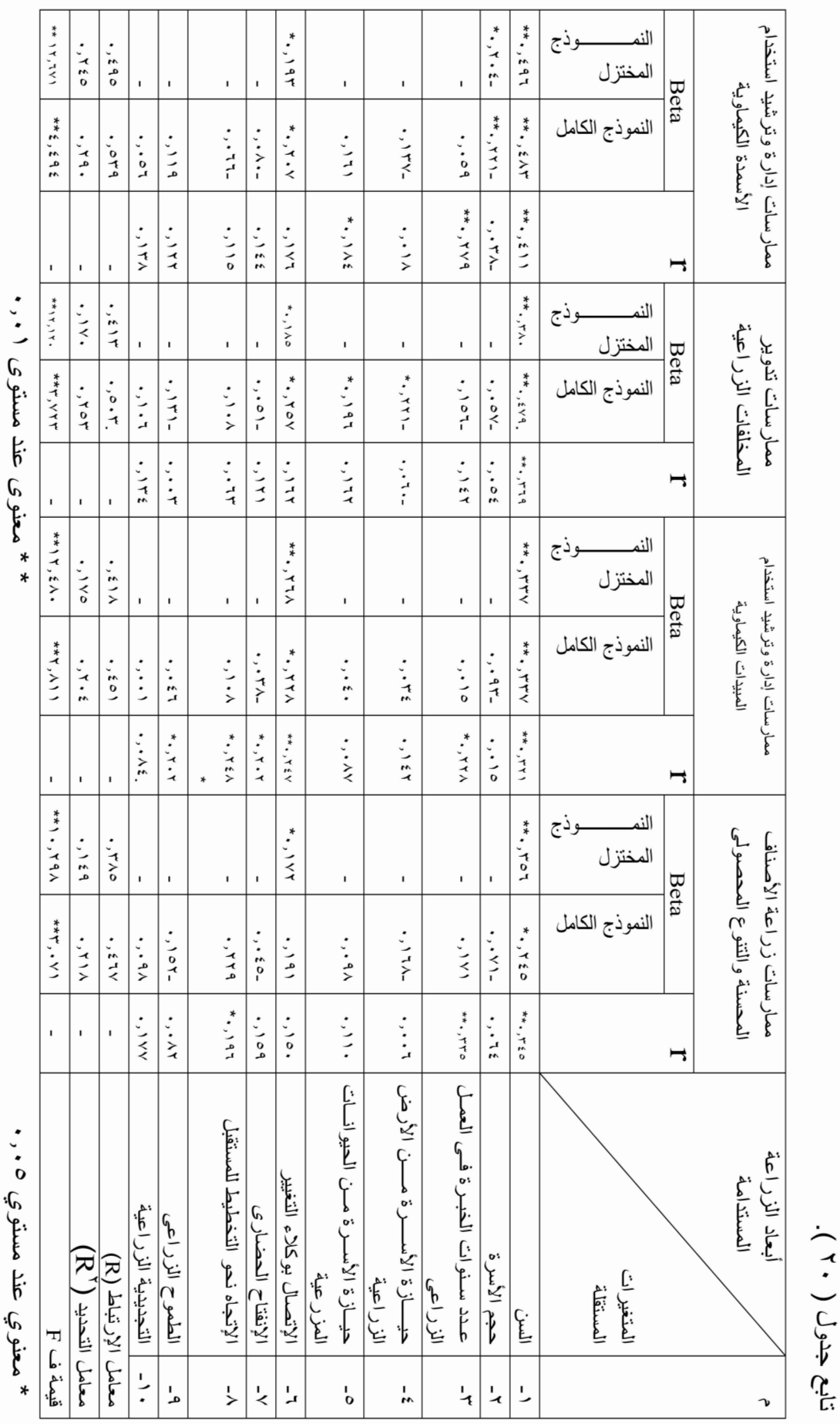

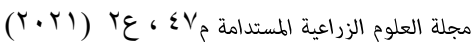




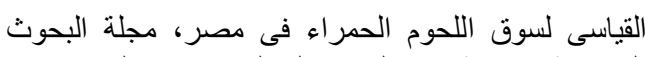

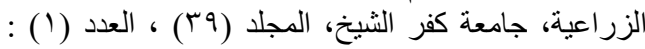

$. \wedge \Lambda-7 \Lambda$

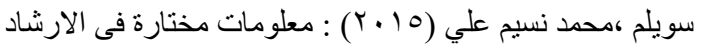

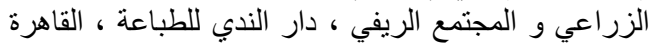

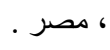

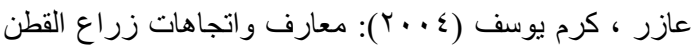

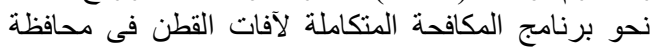

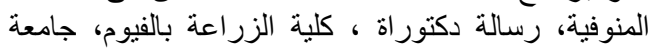

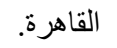

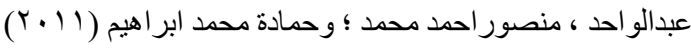

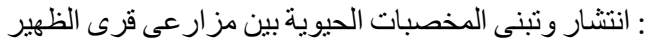

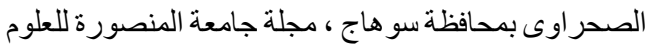

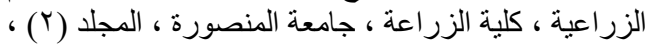

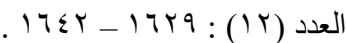

غلوم ، محمد حسين (999 199): النظرية الاجتماعية من بارسونز

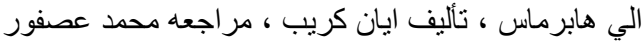

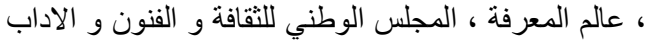
،

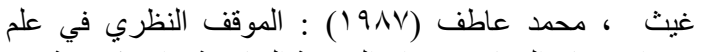
الاجتماع المعاصر ، دار المعرفة الجامعية ، الاسكندرية . له فئرية

سلامة ، فؤاد عبد اللطيف ؛ وفرحات عبد السيد محمد ؛ وسالم

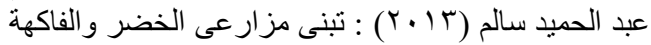

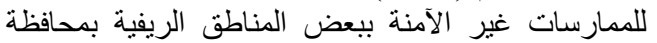

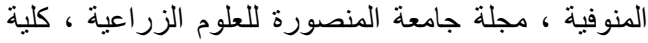

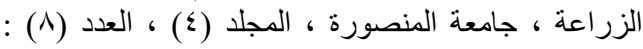
. 1001-10Yr

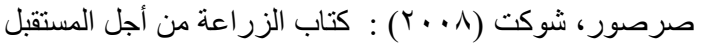

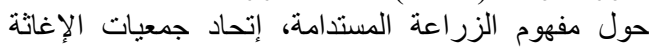
الفلسطينية ، فلسطين.

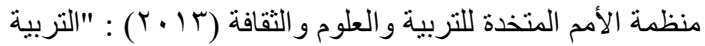

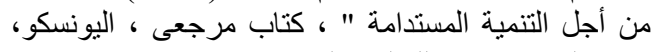

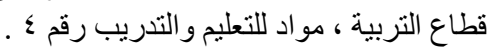

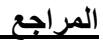

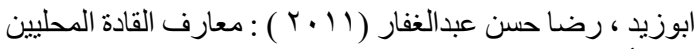

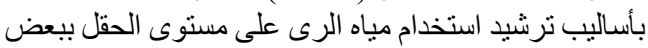

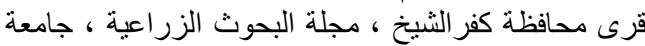

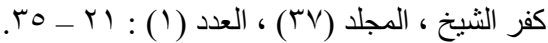

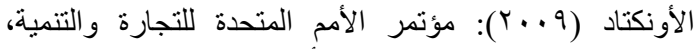

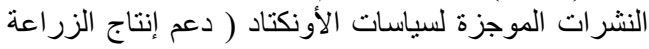

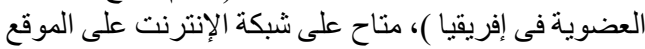

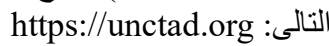

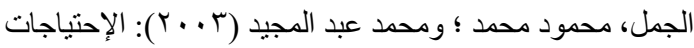

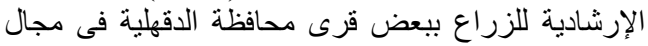

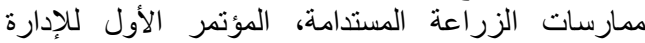

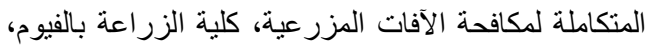

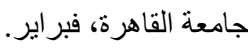

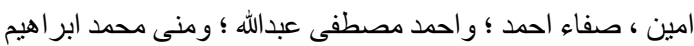

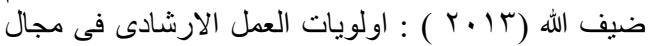

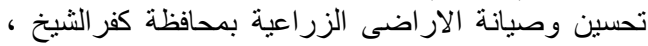

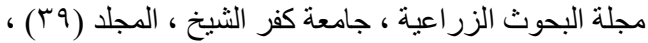

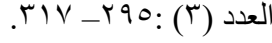

جامع ، محمد نبيل (9V0 1 ) : المفتتح في علم المجتمع ، دار

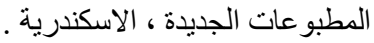

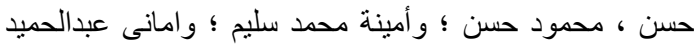

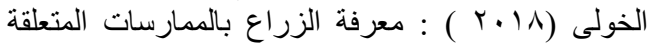

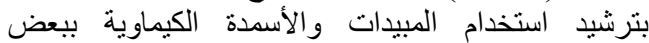

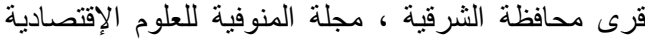

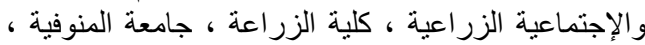

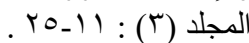

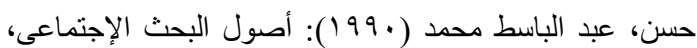
مكتبة وهبه، القاهرة، الطبعة الحادية عشر.

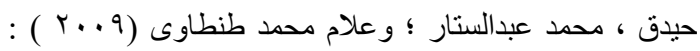

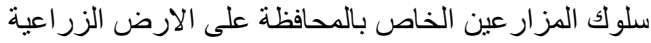

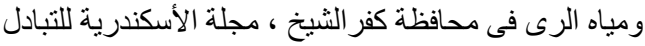

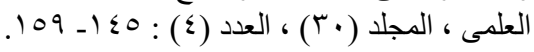

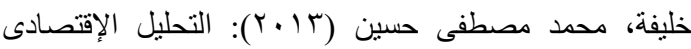


Corelius, K., Wisniewski, S.and Ritchie,M (2001). Sustainable Agriculture: Making Money,Making sense, twenty years of research and resuts: Literature review, The institute for Agriculture trade and policy, Fires of hope,U.S.A.

FAO (1989). Sustainable Development and Natural Resources Management. Twenty-fifth conferences, paper C 8912, Food and Agriclture Organization of the United Nations, Rome.

Farming First Organization (FFO) (2011). SustainableDevelopment promotion Through agriculture,FFO.(on- line) Availale at: http ://www. Farming First.org/ Arabic .

Gips, T. (2002). Sustainable Agriculture, The international alliance For Sustainable Agriculture, University of Minnesota. (on-line) Available at :http://www.mtn.org/iasa/ susagdaf.htm.

Gold,M.V. (2007). Sustainable Agriculture: Definitions and Terms, National Agricultural Library, United States Department of Agriculture (USDA).

Hall,B.and Kapper,G.(1997). Making The transition to Sustainable Farming Fundamentals of Sustainable Agriculture, The national Center for appropriate technology,rural business-cooperative service,U.S. Department of Agriculture (on- line) Available at: http//www.attra. ncat.org.
Liaghoti,H., Veisi, H., Hematyar, H.and Ahmadzadeh, G. (2008). Assessing the students' attiudes towards sustainable agriculture. J. Agric \& Environ. Sci, vol.3,No.2 pp.288-295.

Pasakarnis G.,Maliene V.(2010) " Towards sustainable rural development in central and Eastern Europe: Applying land Consolidation ", Land use policy,vol.27, NO.2,pp:545- 549 .

Rogers, M.E. and Shoemaker,F.F.(1971): Communication Of Innovations Across Cultural approach second edition, The free press, NewYork.

United States Department of Agriculture (USDA) (2009). Natural resource conservation service (NRCS) general manual (180-GM,part407). Available at USDA website:Http: //www.info.usda. gov/default. aspsx?1=select.

Veisi, H., Hematyar, H. and Kerdar, H. (2008). Exploringthe relationship between students' knowledge and perception towards sustainable agriculture,Environmental sciences.vol.5,No.2.

Zubair, H. (2006). "Sustainable Development from an Islamic Perspective: Meaning, implications, and policy concerns ,J.kau: Islamic Econ,vol.19,No.1pp:3-18. 


\title{
Determinants of Farmers' Knowledge of some Sustainable Agricultural Practices in Kafr El-Sheikh Governorate
}

\author{
Tiesseer Kassem Bazina
}

Rural Community Research Department, Agricultural Extension and Rural Development

Research Institute, ARC, Egypt

$\mathbf{T}$ The research aimed at identifying the level of farmers' knowledge of some sustainable agricultural practices, identifying bilateral and multiple relationships between studied independent variables and each of sustainable farming practices, as well as identifying the most contributing variables in explaining the variance in sustainable farming practices. This research was conducted on a systematic random sample of 121 respondents representing $15 \%$ of the total registered farmers in the agricultural association in the village of Bakloula, and the data were collected during June and July 2020, and appropriate statistical methods were used. The results showed that $88.5 \%, 65.3 \%$, $75.2 \%, 69.5 \%, 68.6 \%, 62.8 \%, 52.9 \%$ of the respondents with a high level of knowledge of each of the practices of maintaining irrigation water from pollution, rationalizing the use of irrigation water, maintenance of agricultural land and preserving its fertility, cultivating improved varieties and crop diversity, managing and rationalizing the use of chemical pesticides, recycling agricultural waste, managing and rationalizing the use of chemical fertilizers respectively, and $51.2 \%, 44.6 \%$ of the respondents with an average knowledge level of both Practices of the use of vital and organic fertilizers, and the use of integrated control in the elimination of agricultural pests respectively.It was found that the independent variables studied explain 19.9\%, 19.2\%, 39.8\%, 19.8\%, $27.9 \%, 21.8 \%, 20.4 \%, 25.3 \%, 29 \%$ of the variance in the degree of knowledge of the respondents in each of the practices of maintaining irrigation water from pollution, the use of vital and organic fertilizers, rationalizing the use of irrigation water, the use of integrated control in the elimination of agricultural pests, maintenance of agricultural land and preserving its fertility, cultivating improved varieties and crop diversity, managing and rationalizing the use of chemical pesticides, recycling Agricultural waste, managing and rationalizing the use of chemical fertilizers respectively.Age variable contributed a unique significant contribution to the interpretation of the variance of six dimensions of sustainable agriculture, and the variable communication with the agents of change contributed a unique significant contribution to the interpretation of the variance of five dimensions of sustainable agriculture, while both the variables of agricultural regeneration and urban openness contributed a unique significant contribution in explaining the variance of three dimensions of sustainable agriculture. 